\title{
Comparison of methods to determine methane emissions from dairy cows in farm conditions
}

\author{
P. Huhtanen, ${ }^{* 1}$ E. H. Cabezas-Garcia, ${ }^{*}$ S. Utsumi,† and S. Zimmermanł \\ *Department of Agricultural Research for Northern Sweden, Swedish University of Agricultural Sciences, SE-901 83 Umeå, Sweden \\ †Department Animal Science and Kellogg Biological Station, Michigan State University, Hickory Corners 49060 \\ †C-Lock Incorporated, Rapid City, SD 57702
}

\section{ABSTRACT}

Nutritional and animal-selection strategies to mitigate enteric methane $\left(\mathrm{CH}_{4}\right)$ depend on accurate, costeffective methods to determine emissions from a large number of animals. The objective of the present study was to compare 2 spot-sampling methods to determine $\mathrm{CH}_{4}$ emissions from dairy cows, using gas quantification equipment installed in concentrate feeders or automatic milking stalls. In the first method (sniffer method), $\mathrm{CH}_{4}$ and carbon dioxide $\left(\mathrm{CO}_{2}\right)$ concentrations were measured in close proximity to the muzzle of the animal, and average $\mathrm{CH}_{4}$ concentrations or $\mathrm{CH}_{4} / \mathrm{CO}_{2}$ ratio was calculated. In the second method (flux method), measurement of $\mathrm{CH}_{4}$ and $\mathrm{CO}_{2}$ concentration was combined with an active airflow inside the feed troughs for capture of emitted gas and measurements of $\mathrm{CH}_{4}$ and $\mathrm{CO}_{2}$ fluxes. A muzzle sensor was used allowing data to be filtered when the muzzle was not near the sampling inlet. In a laboratory study, a model cow head was built that emitted $\mathrm{CO}_{2}$ at a constant rate. It was found that $\mathrm{CO}_{2}$ concentrations using the sniffer method decreased up to $39 \%$ when the distance of the muzzle from the sampling inlet increased to $30 \mathrm{~cm}$, but no muzzleposition effects were observed for the flux method. The methods were compared in 2 on-farm studies conducted using 32 (experiment 1) or 59 (experiment 2) cows in a switch-back design of 5 (experiment 1) or 4 (experiment 2) periods for replicated comparisons between methods. Between-cow coefficient of variation (CV) in $\mathrm{CH}_{4}$ was smaller for the flux than the sniffer method (experiment $1, \mathrm{CV}=11.0$ vs. $17.5 \%$, and experiment 2, 17.6 vs. $28.0 \%$ ). Repeatability of the measurements from both methods were high $(0.72-0.88)$, but the relationship between the sniffer and flux methods was weak $\left(\mathrm{R}^{2}=0.09\right.$ in both experiments). With the flux method $\mathrm{CH}_{4}$ was found to be correlated to dry matter intake or body weight, but this was not the case with the sniffer method. The $\mathrm{CH}_{4} / \mathrm{CO}_{2}$ ratio was more highly

Received November 17, 2014

Accepted January 23, 2015.

${ }^{1}$ Corresponding author: pekka.huhtanen@slu.se correlated between the flux and sniffer methods $\left(\mathrm{R}^{2}=\right.$ $0.30)$, and CV was similar (6.4-8.8\%). In experiment 2 , cow muzzle position was highly repeatable $(0.82)$ and influenced sniffer and flux method results when not filtered for muzzle position. It was concluded that the flux method provides more reliable estimates of $\mathrm{CH}_{4}$ emissions than the sniffer method. The sniffer method appears to be affected by variable air-mixing conditions created by geometry of feed trough, muzzle movement, and muzzle position.

Key words: concentration, dairy cow, flux, methane

\section{INTRODUCTION}

Ruminants are increasingly scrutinized for their contributions to greenhouse gas emissions. Ruminants account for up to one-third of the anthropogenic methane $\left(\mathrm{CH}_{4}\right)$ emissions worldwide (IPCC, 2006). Interest has increased in developing various mitigation strategies such as dietary manipulation, additives, and vaccines. In practice, dietary manipulation may still be the most promising. Genetic selection has also been proposed as a strategy to reduce $\mathrm{CH}_{4}$ emissions from ruminant production systems (e.g., Hegarty et al., 2010; PinaresPatiño et al., 2013).

Several methods have been developed to measure $\mathrm{CH}_{4}$ emissions from ruminants. All methods have different scopes of applications, advantages, and disadvantages, and none of them is perfect in all aspects. Respiration chambers provide an accurate reference method used for research purposes. Individual animals are confined in chambers usually for 2 to $4 \mathrm{~d}$, and $\mathrm{CH}_{4}$ emissions are calculated from gas flow and changes in gas concentrations between air inlet and outlet (Yan et al., 2010; Hellwing et al., 2012). The chamber method has both high investment and labor costs, and it could be criticized of distorting feeding behavior. However, no effects on DMI were observed in studies using transparent chambers (Hellwing et al., 2012). The sulfur hexafluoride $\left(\mathrm{SF}_{6}\right)$ tracer technique (Johnson et al., 1994) generates values for $\mathrm{CH}_{4}$ flux that are correlated with chamber measurements, but the between-cow variability was greater than with chamber measurements 
(Grainger et al., 2007; Pinares-Patiño et al., 2011). The method is also relatively labor intensive and, therefore, not suitable for ranking a large number of animals.

More recently, several alternative methods for onfarm measurements based on spot sampling have been proposed. These methods are based on continuous breath analysis of exhaled air from the feed troughs in automatic milking systems (AMS) or concentrate feeders (CF). In one application (sniffer method), a sampling inlet is placed in the feed trough of an AMS, and gas concentrations in exhaled air are continuously sampled. Following this principle, Garnsworthy et al. (2012) developed an on-farm method based on an index of $\mathrm{CH}_{4}$ emission that is calculated during each milking as the product of peak frequency and mean peak area of $\mathrm{CH}_{4}$ concentration. In another similar application of the sniffer method, $\mathrm{CH}_{4}$ and $\mathrm{CO}_{2}$ concentrations are used to derive a $\mathrm{CH}_{4} / \mathrm{CO}_{2}$ ratio, which is then multiplied by estimated $\mathrm{CO}_{2}$ production to predict $\mathrm{CH}_{4}$ fluxes (Madsen et al., 2010; Lassen et al., 2012). A recently patented gas-flux quantification system (GreenFeed; C-Lock Inc., Rapid City, SD) was implemented in feed troughs of AMS or in CF. This system uses a similar principle for measuring gas emissions as for respiration chambers (flux method) where an active airflow is induced to capture emitted air. This system integrates measurements of air flow, gas concentrations, and detection of muzzle position to allow direct measurement of $\mathrm{CH}_{4}$ and $\mathrm{CO}_{2}$ fluxes to be measured during each animal visit to the feed trough.

Studies using the sniffer method have reported emissions with relatively high between-animal CV (Garnsworthy et al., 2012; Lassen and Løvendahl, 2013; Bell et al., 2014a) compared with data from studies using respiration chambers (Blaxter and Clapperton, 1965; Yan et al., 2010) or the flux method (Zimmerman et al., 2013). These results suggest that the sniffer method may result in a greater CV compared with the flux method based on spot sampling. The objective of this study was to evaluate $\mathrm{CH}_{4}$ emissions estimated by the sniffer and flux methods. Specific objectives were to assess relationships of emissions between the 2 methods, repeatability of gas measurements, and suitability of methods to sort or rank animals according to $\mathrm{CH}_{4}$ emissions.

\section{MATERIALS AND METHODS}

A laboratory verification study and 2 on-farm studies were conducted to compare the sniffer and flux methods. The laboratory study assessed the influence of various animal- and environment-related factors that can influence the measurements of captured gas under controlled laboratory conditions. The 2 on-farm studies were conducted to assess methods under typical farm conditions. One farm study implemented a CF (experiment 1) that provided concentrates to each animal multiple times per day. The other farm study implemented the same gas quantification system retrofitted in the feed trough of an AMS (experiment 2).

\section{Equipment}

A data-acquisition system was used (C-Lock Inc.) that recorded ambient pressure, temperature, humidity, $\mathrm{CH}_{4}$ and $\mathrm{CO}_{2}$ concentrations by nondispersive infrared sensors (max span: $\mathrm{CO}_{2}=0-4 \%, \mathrm{CH}_{4}=0-2 \%$ ), muzzle position, pipe airflow rate (flux method only), and radiofrequency identification ear tags specific to each cow. All variables were logged at 1 -s intervals.

For the laboratory study, and one farm study (experiment 1 ), the data-acquisition system was built into a specialized semienclosed CF manufactured by C-Lock Inc. (Figure 1). In the AMS farm study (experiment 2), the data-acquisition system and sensors were custom fit into the existing feed trough of an A3 Astronaut milking unit (Lely Industries N. V., Maassluis, the Netherlands), using a specially designed air-collection manifold (Figure 2). All gas sensors were the same between the $\mathrm{CF}$ and AMS, with the primary difference being the geometry of the feed trough.

The volume of the feed trough was larger in the AMS than in the CF (70 vs. $30 \mathrm{~L}$ ). Therefore, while a cow is using the AMS, the cow can more easily move its muzzle out of the feed trough by lifting it quickly upward or side to side. In contrast, in the CF, the cow must step backward to remove the muzzle, therefore limiting the in-out head movement. In an AMS, the cows are locked in the milking stall until milking is complete. In most cases cows may not eat all of the delivered concentrates, or they may eat all delivered concentrate before milking is finished. Because of the difference in geometry of manifolds and muzzle movement, different sensors were used to determine muzzle position relative to the air-sampling inlet. In the CF, an infrared distance sensor was placed inside the feed trough just above the sampling inlet to scan outward and measure the distance between the muzzle and sampling inlet. In the AMS, an infrared beam sensor was positioned inside the trough so when the muzzle of the cow broke the beam a signal was sent to the data logger (Figure 2 ), which allowed for the determination of the duration of time the head was inside the feed trough during each milking period.

Equipment Setup. Subsampling of air for the sniffer method was extracted at approximately $1 \mathrm{~L} /$ min close to the muzzle of the cow, either directly in the middle of the feed trough for the CF (Figure 3) or on the left side 


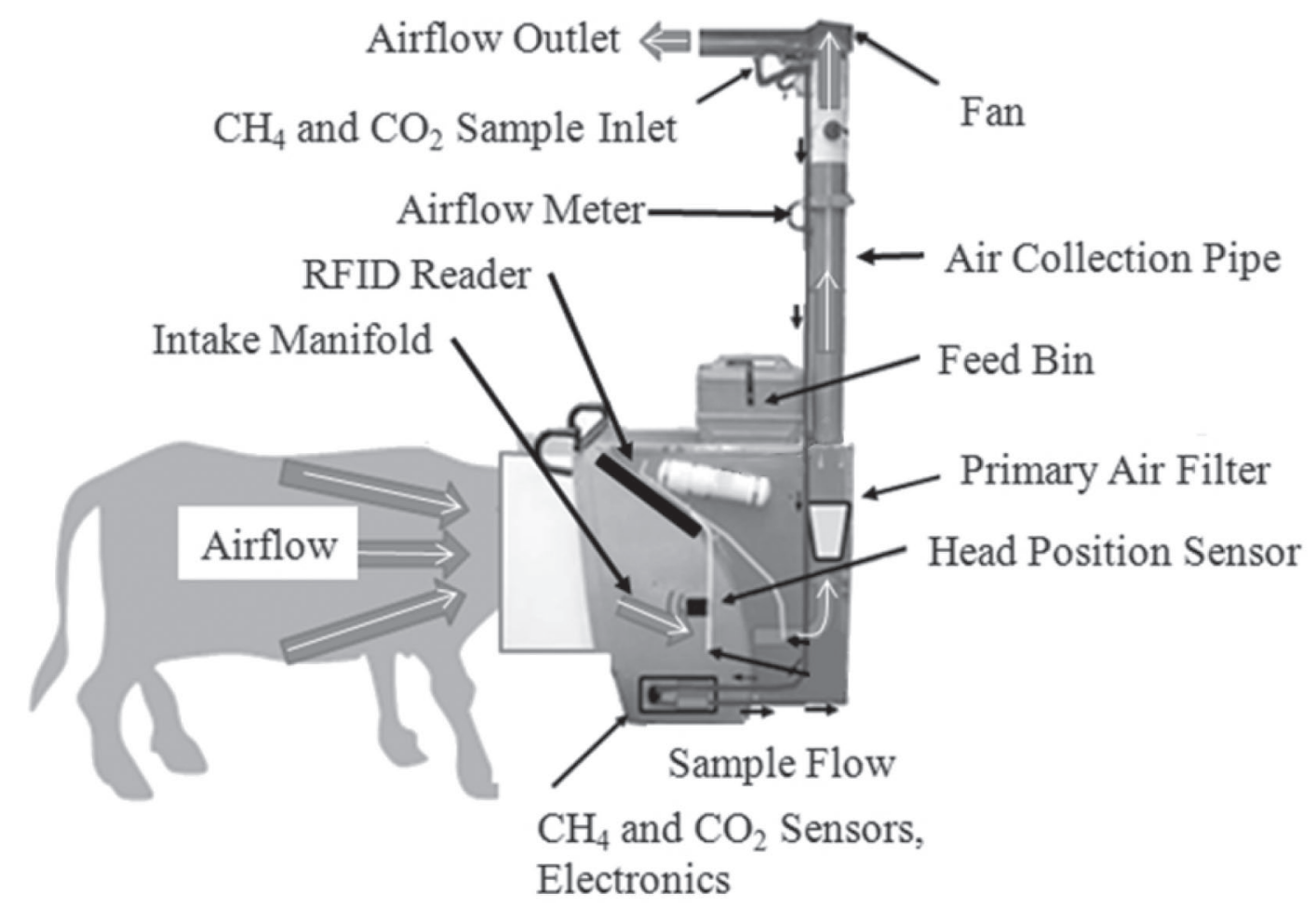

Figure 1. Layout of the GreenFeed (C-Lock Inc., Rapid City, SD) system used for this study (the flux method). RFID = radiofrequency identification.

of the feed chute for the AMS (Figure 2). For the sniffer method in the AMS, the location of the sampling point was selected based on Garnsworthy et al. (2012). The sample was then routed through a 7.0- $\mu \mathrm{m}$ air filter into the $\mathrm{CH}_{4}$ and $\mathrm{CO}_{2}$ sensors. The airflow fan was set to "off" during the sniffer-method measurements.

For the flux method, the equipment fan was turned to "on" to induce a measured air flow in the collection pipe of 1,200 to $1,600 \mathrm{~L} / \mathrm{min}$ (AMS) and 1,560 to 2,250 $\mathrm{L} / \mathrm{min}(\mathrm{CF})$. The collected gases were thoroughly mixed in the air-collection pipe and filtered to remove dust and other particulates. The samples for $\mathrm{CH}_{4}$ and $\mathrm{CO}_{2}$ analysis were extracted at $1 \mathrm{~L} / \mathrm{min}$ downstream of the fan after the sample was mixed and routed into the 7.0$\mu \mathrm{m}$ air filter and then into the nondispersive infrared sensors for continuous measurement of gas concentrations on a 1-s basis. Airflow was also measured on a 1-s basis using a hot-film anemometer (JLC International, New Britain, PA). The airflow meter was calibrated in a wind-tunnel to a tolerance of $\pm 3 \%$. In addition, $\mathrm{CO}_{2}$ recovery testing was performed to confirm the entire system calibration.

Laboratory Experiment Design. The effect of air turbulences and diffusive gas processes created by a cow (breathing, movement, and so on) was replicated using a scale-model "cow head" system (Figure 4). The model cow head "breathed" in and out with mechanical lungs created from 2 coupled bellows pumps (Intex, Long Beach, $\mathrm{CA}$ ) that emitted $\mathrm{CO}_{2}$ at a controlled rate $\left(\mathrm{CO}_{2}=10,690 \pm 504 \mathrm{~g} / \mathrm{d}\right)$. Carbon dioxide was used as a test gas because most $\mathrm{CO}_{2}$ is emitted from a cow at a continuous respiration frequency, whereas most of the $\mathrm{CH}_{4}$ is released by discontinuous eructation pulses that occur only about once every 45 to $60 \mathrm{~s}$. Thus emissions of $\mathrm{CO}_{2}$ are steadier than $\mathrm{CH}_{4}$, thereby providing more steady test conditions for comparisons of the 2 methods. Tidal volume, or size of inhalations and exhalations by the model cow head, were controlled by a foot pump that sucked and blew air from its nostrils at a rate of 3.5 or $4.7 \mathrm{~L} /$ breath and at $10^{\circ} \mathrm{C}$ (Stevens, 1981). Breaths were created by manually oscillating the foot pump to a metronome rhythm to simulate 30 and 60 breaths per min. The higher rate of 60 breaths per minute could indicate a heat-stress condition.

Two previously tested and identical CF units were used side by side, one for the sniffer method and one for the flux method. Common calibrations and recoveries were completed on both units to ensure no bias between the units. The 2 units operated and logged data simultaneously. A testing matrix was developed to examine the effects on recovered emissions of various muzzle positions of the model cow head relative to 


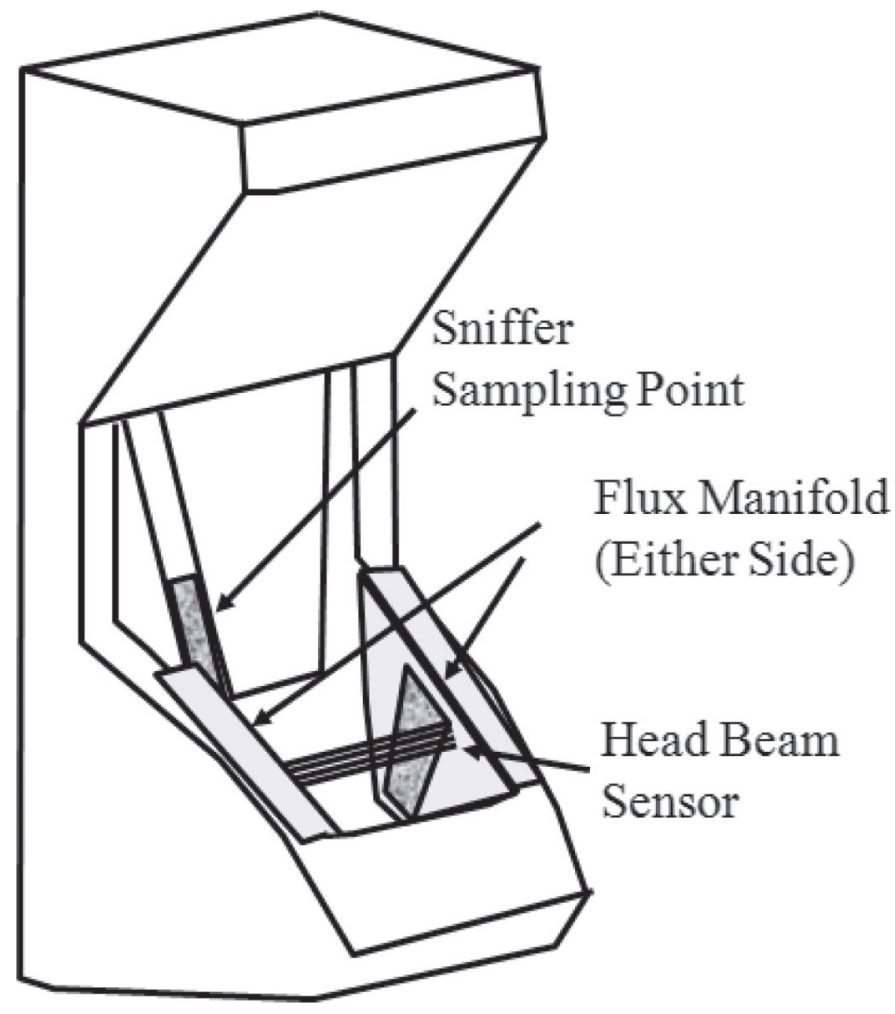

Figure 2. Layout of the retrofitted feed trough located in the automatic milking system. The flux method used a manifold fit into the feed trough with airflow intakes located on both sides of the manifold close to the nose of the cow. For the sniffer method, the sampling inlet was located in the back, left side of the feed trough. An inferred beam sensor indicated whether the muzzle of the animal was inside the feed trough.

the sampling inlet, head movement, breathing patterns, and wind conditions (Table 1). For each test configuration, 5 repeated runs of 3 -min gas-release events were completed. The implementation of the model cow head was randomly alternated between the $\mathrm{CF}$ units to allow replicated comparisons of the sniffer and flux methods under various conditions. The sequential releases of gas into each unit ensured that the $\mathrm{CO}_{2}$ releases were consistent for all tests.

\section{Farm Studies}

On-Farm Study with Concentrate Feeding System (Experiment 1). All procedures involving animals were approved by the Regional Ethics Committee of the Swedish University of Agricultural Sciences, Umeå, Sweden. Comparison of the on-farm $\mathrm{CH}_{4}$ measurement methods was conducted in connection with a feeding experiment with 32 Swedish Red dairy cows (25\% primiparous) housed in an air-conditioned research barn, milked twice daily in a milking parlor, and with continuous access to fresh water.

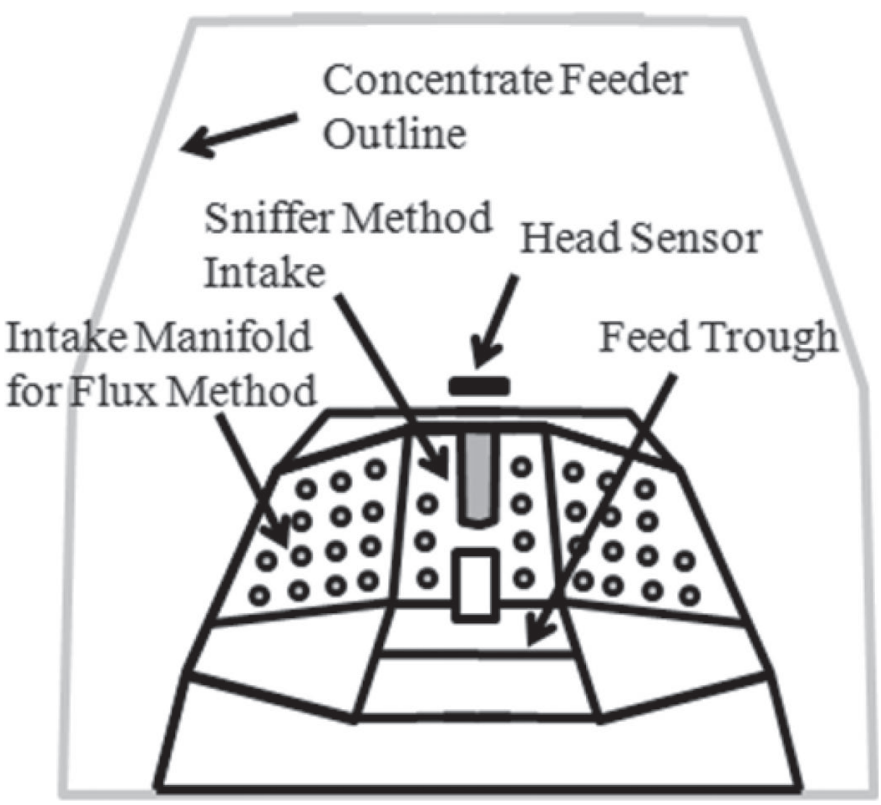

Figure 3. The sniffer-method configuration used in laboratory and farm studies.

At the beginning of experiment the average $( \pm \mathrm{SD})$ BW, milk yield, DMI, and DIM were $664 \pm 72 \mathrm{~kg}, 30.2$ $\pm 6.3 \mathrm{~kg} / \mathrm{d}, 20.1 \pm 2.8 \mathrm{~kg} / \mathrm{d}$, and $134 \pm 34 \mathrm{~d}$, respectively. The experimental design was a cyclic changeover with 4 blocks of 8 cows, 8 diets and 3 experimental periods of $21 \mathrm{~d}$. The 8 treatments were in a $2 \times 4$ factorial arrangement of treatments consisting of 2 forages (grass vs. grass-red clover mixtures), each fed 4 levels of CP. Dietary CP concentration was increased by gradually replacing ensiled barley grain with canola expeller (Öpex; Mildola Ltd., Kantvik, Finland). The diets were fed ad libitum as TMR (60\% forages, $40 \%$ concentrates on DM basis). The feed intake was recorded using an automatic measurement system (Insentec Ltd., Lemelerveld, the Netherlands). In addition, the cows received a commercial concentrate mixture from 2 $\mathrm{CF}$ units. The cows were allowed to visit the $\mathrm{CF}$ units every $7 \mathrm{~h}$, and they were given 8 servings of $50 \mathrm{~g}$ of concentrate at 40-s intervals during each $\mathrm{CF}$ visit. The feeder had already been stationed for 15 mo; therefore, the cows were well conditioned to using the CF.

On-Farm Study with Automatic Milking System (Experiment 2). All procedures involving animals were approved by the Michigan State University's Animal Use and Care Committee (Project: 02/14-024$00)$. The study was conducted in connection with a long-term study focusing on lactation profiles of $\mathrm{CH}_{4}$ and $\mathrm{CO}_{2}$ emissions from dairy herds. Two AMS at the W. K. Kellogg Biological Station dairy farm, Hickory Corners, Michigan, were retrofitted with the snifferand flux-method equipment. The herd comprised 107 

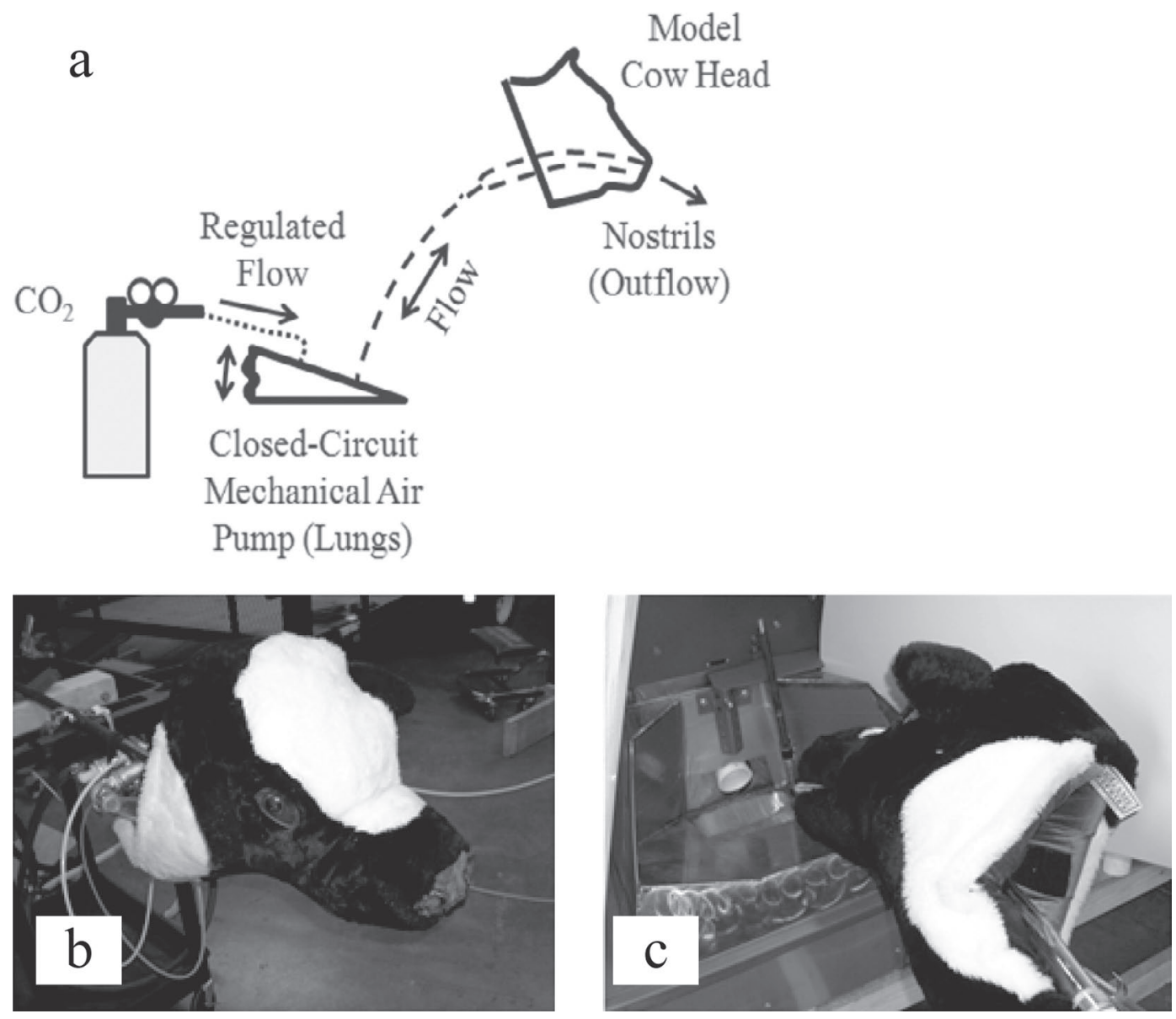

Figure 4. (a) The layout of the model cow head used in the studies. Two bellows pumps were used to simulate the lungs of a cow, and $\mathrm{CO}_{2}$ was injected into the lungs and released through the nostrils of the animal to simulate breathing. (b, c) The model cow head used in the study. Nostrils were placed into the cow head to best simulate the flow patterns near the muzzle of a cow.

Holstein-Friesian cows (31\% primiparous), and 35, 12, or $53 \%$ were in early $(<102$ DIM), mid (103 to 204 DIM), or late (>204 DIM) lactation, respectively. At the beginning of the study, cows were evenly divided into 2 groups, 1 group for each AMS $(\mathrm{n}=54$ and $\mathrm{n}$ $=53$ ), balanced for parity and DIM. The average BW was $675 \pm 96 \mathrm{~kg}$ and milk yield was $29.5 \pm 12.5 \mathrm{~kg} / \mathrm{d}$. The daily BW change of cows over the entire study was $0.55 \pm 0.7 \mathrm{~kg} / \mathrm{d}$. The study lasted $40 \mathrm{~d}$ and comprised 4 periods of $10 \mathrm{~d}$ for comparison between the sniffer and flux methods, using a switch-back design: fluxsniffer-flux-sniffer (AMS 1) and sniffer-flux-snifferflux (AMS 2). Cows were given unrestricted amounts of mixed ration $(60 \%$ forages, $40 \%$ concentrates on a DM basis; $\mathrm{DM}=39.4 \% ; \mathrm{NE}_{\mathrm{L}}=1.67 \mathrm{Mcal} / \mathrm{kg} ; \mathrm{CP}=16.8 \%$; $\mathrm{NDF}=36.8 \%)$. The cows were group fed 3 times per day at 0500,1200 , and $2100 \mathrm{~h}$ and pushed throughout the day as needed. Amount of mixed ration offered and orts were recorded daily, and the average consumption of mixed ration was determined as the difference between amount offered and orts, divided by the number of cows. In addition, the cows received a commercial concentrate pellet $(\mathrm{DM}=89.4 \% ; \mathrm{CP}=19.3 \%$; $\mathrm{NDF}=$ $9.9 \% ; \mathrm{NE}_{\mathrm{L}}=2.05 \mathrm{Mcal} / \mathrm{kg}$ ), fed during milking in the AMS at a rate of $1 \mathrm{~kg}$ of pellet per $7 \mathrm{~kg}$ of milk. Cows that were freshening and entering the lactating herd and the cows that were dried off and removed from the lactating herd during the study were excluded from the final analysis.

A sensitivity analysis was performed on the data set from experiment 2 to examine the relationship between muzzle position and gas fluxes as measured by the flux method. In one analysis, the data were not filtered for muzzle position, and in the other analysis the data were filtered for muzzle position. The analysis was based on 96 cows that completed the study and had recorded data during all 4 periods. The fraction of time during milking when the muzzle of the cow was detected 
Table 1. Test matrix of emissions releases from the model cow head ${ }^{1}$

\begin{tabular}{|c|c|c|c|c|c|c|c|c|c|c|c|}
\hline \multirow[b]{2}{*}{ Item } & \multirow{2}{*}{$\begin{array}{c}\text { Tidal } \\
\text { volume, L }\end{array}$} & \multirow{2}{*}{$\begin{array}{l}\text { Volume of } \\
\text { feed trough, L }\end{array}$} & \multirow{2}{*}{$\begin{array}{l}\text { Breath } \\
\text { rate, } \\
\mathrm{L} / \mathrm{min}\end{array}$} & \multirow{2}{*}{$\begin{array}{l}\text { Head } \\
\text { orientation }\end{array}$} & \multirow{2}{*}{$\begin{array}{l}\text { Muzzle distance } \\
\text { to sampling } \\
\text { point, } \mathrm{cm}\end{array}$} & \multirow{2}{*}{$\begin{array}{l}\text { Static or } \\
\text { moving }\end{array}$} & \multirow{2}{*}{$\begin{array}{l}\text { Wind } \\
\text { speed, } \\
\mathrm{m} / \mathrm{s}\end{array}$} & \multicolumn{2}{|c|}{ Relative response, \% } & \multicolumn{2}{|c|}{$\mathrm{CV}, \%$ of releases } \\
\hline & & & & & & & & Flux $^{2}$ & Sniffer $^{3}$ & Flux & Sniffer \\
\hline 1 & 3.5 & 30 & 111 & Vertical $^{4}$ & 0 & Static & 0 & 100 & 100 & 2.9 & 9.8 \\
\hline 2 & 3.5 & 30 & 111 & Vertical & 10 & Static & 0 & 100 & 73 & 2.6 & 20.9 \\
\hline 3 & 3.5 & 30 & 111 & Vertical & 30 & Static & 0 & 98 & 78 & 5.9 & 29.8 \\
\hline 4 & 3.5 & 30 & 111 & $45^{5}$ & 0 & Static & 0 & 97 & 107 & 2.6 & 10.8 \\
\hline 5 & 3.5 & 30 & 111 & 45 & 10 & Static & 0 & 101 & 114 & 2.1 & 10.6 \\
\hline 6 & 3.5 & 30 & 111 & 45 & 30 & Static & 0 & 101 & 70 & 1.0 & 23.0 \\
\hline 7 & 3.5 & 47 & 111 & Vertical & 0 & Static & 0 & 103 & 85 & 0.9 & 15.2 \\
\hline 8 & 3.5 & 47 & 111 & Vertical & 10 & Static & 0 & 103 & 55 & 2.7 & 45.5 \\
\hline 9 & 3.5 & 47 & 111 & Vertical & 30 & Static & 0 & 104 & 94 & 1.2 & 14.1 \\
\hline 10 & 3.5 & 30 & 141 & Vertical & 0 & Static & 0 & 98 & 100 & 3.5 & 12.0 \\
\hline 11 & 3.5 & 30 & 141 & Vertical & 10 & Static & 0 & 100 & 63 & 3.7 & 21.0 \\
\hline 12 & 3.5 & 30 & 141 & Vertical & 30 & Static & 0 & 97 & 48 & 1.3 & 33.1 \\
\hline 13 & 4.7 & 30 & 282 & Vertical & 0 & Static & 0 & 102 & 93 & 5.9 & 11.1 \\
\hline 14 & 4.7 & 30 & 282 & Vertical & 10 & Static & 0 & 107 & 68 & 1.4 & 19.2 \\
\hline 15 & 4.7 & 30 & 282 & Vertical & 30 & Static & 0 & 101 & 48 & 4.3 & 33.2 \\
\hline 16 & 3.5 & 30 & 111 & Vertical & $\mathrm{NA}^{6}$ & Moving ${ }^{7}$ & 0 & 106 & 102 & 2.4 & 20.0 \\
\hline 17 & 3.5 & 30 & 111 & Vertical & $\mathrm{NA}$ & Moving 8 & 0 & 103 & 91 & 0.6 & 10.4 \\
\hline 18 & 3.5 & 30 & 111 & Vertical & 0 & Static & $6^{9}$ & 85 & 33 & 7.2 & 28.9 \\
\hline 19 & 3.5 & 30 & 111 & Vertical & 10 & Static & 6 & 83 & 13 & 5.1 & 4.0 \\
\hline
\end{tabular}

For every test position five 3-min recovery tests were carried out in duplicate and alternated between the flux and sniffer methods.

${ }^{2}$ The flux response is the average recovery rate of gas.

${ }^{3}$ The sniffer response is the average concentration for the release compared with a reference concentration; the reference was $0 \mathrm{~cm}$ of muzzle distance from the sampling inlet in a vertical head position.

$\stackrel{{ }^{4}}{ }$ Reference point for the sniffer method.

${ }^{5} \mathrm{~A} 45^{\circ}$ tilt of the head.

№t analyzed.

o ${ }^{7}$ Side-to-side movement.

₹. $\quad{ }^{8} \mathrm{In}$-out movement.

( ${ }^{9}$ Wind was directed into the feed trough from behind. 
by the beam sensor to be inside the feed trough was measured and calculated for every cow milking event.

\section{Calculations}

Flux-Method Calculations. The calculation of gas flux $(\mathrm{g} / \mathrm{d})$ used the same principle as in respiration studies (McLean and Tobin, 1987). The volumetric flow rates of gases $\left(Q_{c} ; \mathrm{L} / \mathrm{min}\right)$ were determined using the following equation:

$$
Q_{\mathrm{c}(i)}=\left[C_{\mathrm{p}(i)} \times\left(\operatorname{Conc}_{(i)}-\mathrm{BConc}_{(i)}\right) \times Q_{\mathrm{air}(i)}\right] / 10^{6},
$$

where $C_{\mathrm{p}}$ is the fractional capture rate of air at any time $(i)$ determined experimentally to be 1.0 for indoor farm conditions without wind, Conc is the concentration of captured gas (ppm), BConc is the background concentration of gas (ppm), and $Q_{\text {air }}$ is the volumetric airflow rate $(\mathrm{L} / \mathrm{min})$ measured on a dry-gas basis at 1 atm, determined as follows,

$$
Q_{\operatorname{air}(i)}=60 \times V_{\mathrm{m}(i)} \times V_{\mathrm{adj}(i)} \times A_{\mathrm{p}} \times 1,000,
$$

where $A_{\mathrm{p}}$ is the cross-sectional area of the pipe (0.00811 $\left.\mathrm{m}^{2}\right) ; V_{\mathrm{m}}$ is the air velocity at the center of the pipe $(\mathrm{m} / \mathrm{s})$, automatically adjusted by the velocity sensor for dry gas at $1 \mathrm{~atm}$ of pressure; and $V_{\text {adj }}$ is the correction factor $(0.88)$ that converts $V_{\mathrm{m}}$ to an average pipe velocity.

Once $Q_{\mathrm{c}}$ is known, the ideal gas law is used to determine the mass flux $\left(Q_{\mathrm{m}}\right)$ at any time $(i)$ :

$$
Q_{\mathrm{m}(i)}=Q_{\mathrm{c}(i)} \times 273.15 /\left(273.15+T_{\operatorname{air}(i)}\right) \times \rho_{\mathrm{c}},
$$

where $T_{\text {air }}$ is the air temperature $\left({ }^{\circ} \mathrm{C}\right)$ and $\rho_{\mathrm{c}}$ is the density of gas at $1 \mathrm{~atm}$ and $273.15 \mathrm{~K}(0.717$ and $1.977 \mathrm{~g} / \mathrm{L}$ for $\mathrm{CH}_{4}$ and $\mathrm{CO}_{2}$, respectively). The flux calculations were performed at 1 -s intervals.

The BConc of $\mathrm{CH}_{4}$ and $\mathrm{CO}_{2}$ were determined using the ambient air concentrations measured just before and after the cow visit when the ambient gas concentrations were stable. Thereafter, BConc during the cow visit was calculated by linearly interpolating across time between the starting and ending background concentrations. In the testing conditions, this assumption provided an accurate estimation of BConc.

Daily fluxes by individual cows were calculated as the average of all flux measurements within a study period. This calculation included multiple gas samples (20 to 30 samples per cow) collected at different hours of the day, thereby minimizing temporal effects associated with changes in diurnal feeding cycles among cows or study periods (Hegarty, 2013).
Sniffer-Method Calculations. The concentration increase (SConc) of gas during a cow visit was determined as follows:

$$
\begin{gathered}
\operatorname{SConc}_{(i)}=\left(\operatorname{Conc}_{(i)}-\operatorname{BConc}_{(i)}\right) \times\left(P_{1(i)} \times 273.15\right) / \\
{\left[100 \times\left(273.15+T_{1(i)}\right)\right] .}
\end{gathered}
$$

This calculus assumed a constant mass flux of emission from the cow; therefore, out-flowing concentrations of gas from the cow were affected by air density. The air ambient density was adjusted to standard conditions using the ambient pressure $\left(P_{i} ; \mathrm{kPa}\right)$ and the ambient temperature $\left(T_{i} ;{ }^{\circ} \mathrm{C}\right)$ measured at time $(i)$. The determination of BConc was conducted as described above for the flux method. Similar to the flux method, the average concentration of gases emitted by individual cows was the average of all gas measurements collected within a study period.

Filtering of Data. The 1-s flux data (flux method) or concentration-increase data (sniffer method) during visits were integrated for each event to determine the total mass of emitted gas (flux method), or total area of gas concentration under the curve (sniffer method), and the total time of each event. Events were determined by continuously calculating the slope of the 1-s $\mathrm{CH}_{4}$ concentration measurements and using slope changes to define the start and stop time of each eructation peak. Time periods when eructation did not occur but a cow was present were also considered as separate events. Next, individual events were removed if they did not satisfy the criteria described in the following paragraph. Finally, total mass flux (flux method) or average concentration area (sniffer method) of all qualifying events during a specific cow visit were summed and divided by duration time for each cow visit. The final result was either the average mass flux per visit (flux method) or average concentration per visit (sniffer method). The sniffer-method calculations were similar to the methodology described by Garnsworthy et al. (2012).

For the flux method for both the AMS and CF, and for the sniffer method in the $\mathrm{CF}$, the selection of qualifying events was based on the muzzle-position sensor. Only events where the muzzle was close to the sampling inlet $(<30 \mathrm{~cm})$ were defined as qualifying events and used in the calculations. In the $\mathrm{CF}$, the muzzle sensor provided a real-time measurement of the distance of the muzzle from the sampling inlet for both sniffer and flux methods.

However, because of the different feed-trough geometry for the sniffer method in the AMS, the muzzle sensor may not accurately determine the muzzle orientation relative to the sampling inlet (Figure 2). In some 
instances, it was possible that the muzzle of the cow did not break the beam, but the muzzle was oriented directly toward the sniffer-method sampling inlet. To filter the data for the sniffer method in the AMS, similar criteria as defined by Garnsworthy et al. (2012) was used, which assumes any eructation peak over an arbitrary threshold is to be included in the resulting totals $\left(\mathrm{CH}_{4}\right.$ peak $>395 \mathrm{ppm}$ was used in this analysis $)$. The final filtering criteria implemented for both methods was that at least $3 \mathrm{~min}$ of qualifying event data was needed for the visit to be used in the data set.

Calibration. Calibrations of the $\mathrm{CH}_{4}$ and $\mathrm{CO}_{2}$ sensors were performed during all tests, and recovery testing for the flux method was also performed. For calibrations, the output sensor signal was linearized throughout the sensor range, and calibration was determined by a 2-point calibration of known low and high standard gas. The low standard gas mixture was either $0 \mathrm{ppm}$ of $\mathrm{CH}_{4}$ and $\mathrm{CO}_{2}$ (experiment 1, AGA Gas Ltd., Enköping, Sweden) or $500 \mathrm{ppm}$ of $\mathrm{CH}_{4}$ and 1,500 ppm of $\mathrm{CO}_{2}$ (experiment 2, Matheson Tri-Gas Inc., Basking Ridge, NJ), and the high concentration was 1,010 ppm of $\mathrm{CH}_{4}$ and $10,000 \mathrm{ppm}$ of $\mathrm{CO}_{2}$ (experiment 1, AGA Gas Ltd.) or 1,500 $\mathrm{ppm}$ of $\mathrm{CH}_{4}$ and $10,000 \mathrm{ppm}$ of $\mathrm{CO}_{2}$ (experiment 2, Matheson Tri-Gas Inc.). The balance gas in all cases was nitrogen. For the flux method, gas-recovery testing was performed by a controlled release of $\mathrm{CO}_{2}$ from a gas cylinder over 3 min into the $\mathrm{CF}$ or AMS manifold. The 3-min releases were repeated 6 times in experiment 1 and 12 times in experiment 2. The mean recoveries of $\mathrm{CO}_{2}$ were $102.1 \%$ and $\mathrm{SE}=2.7 \%$ (experiment 1 ) and $97.7 \%$ and $\mathrm{SE}=$ $1.0 \%$ (experiment 2).

\section{Statistical Analysis}

All descriptive statistics (laboratory experiment) and statistical analysis (on-farm studies) were conducted with the SAS statistical package (SAS Institute, 2008). Gas data from the on-farm studies data were analyzed with linear mixed models, using the MIXED procedure in SAS (SAS Institute, 2008):

$$
y_{i j k}=\mu+P_{i}+D_{j}+C_{k}+\beta_{1} \times \mathrm{DMI}+e_{i j k},
$$

where $y_{i j k}$ is the dependent variable $\left[\mathrm{CH}_{4}, \mathrm{CO}_{2}\right.$, or $\mathrm{CH}_{4} /$ $\mathrm{CO}_{2}$; number of visits; muzzle position (experiment 2 only)]; $\mu$ is the overall mean; $P$ and $D$ (experiment 1 only) are fixed effects of period and diet; $\beta_{1}$ is the linear regression coefficient for DMI (experiment 1 only); $C_{k}$ is the random effect of cow; and $e_{i j k}$ is the random residual effect.
Repeatability (Rep) was calculated as

$$
\operatorname{Rep}=\delta_{\text {cow }}^{2} /\left(\delta_{\text {cow }}^{2}+\delta_{\text {residual }}^{2}\right),
$$

where $\delta^{2}$ is variance.

The relationships between concentrations of $\mathrm{CH}_{4}$ and $\mathrm{CO}_{2}$ or $\mathrm{CH}_{4} / \mathrm{CO}_{2}$ ratio and corresponding fluxes were estimated by linear regressions using least squares means, which were estimated for each animal using the following linear model:

$$
Y_{i j}=\mu+P_{i}+D_{j}+X_{i j}+e_{i j},
$$

where $Y_{i j}$ is the dependent variable $\left(\mathrm{CH}_{4}, \mathrm{CO}_{2}\right.$, or $\mathrm{CH}_{4}: \mathrm{CO}_{2}$ measured by the flux method), $\mu$ is the overall intercept, $P$ and $D$ are the effects of period (experiment 1 and 2) and diet (only in experiment 1), $X_{i j}$ is the independent variable $\left(\mathrm{CH}_{4}, \mathrm{CO}_{2}\right.$, or $\mathrm{CH}_{4}: \mathrm{CO}_{2}$ measured by the sniffer method), and $e_{i j}$ is the random residual effect.

For the AMS data, repeatability of the fraction of time the muzzle of the cow was inside in the feed trough and gas measurements were calculated according to the following MIXED model:

$$
y_{i j k l}=\mu+P_{i}\left(R_{j}\right)+D_{k}\left(P_{i}\right)+C_{l}+e_{i j k l},
$$

where $y_{i j k l}$ is the dependent variable; $\mu$ is the overall mean; $P(R)$ is the fixed effect of period within an AMS robot unit; $D(P)$ and $C$ are random effects of day within period and animal, respectively; and $e_{i j k l}$ is the random residual effect. Repeatability was estimated according to model [6].

Finally, the effect of muzzle position $(\mathrm{MuP})$, which was calculated as the fraction of time with head in the feed trough during milking, on $\mathrm{CH}_{4}$ and $\mathrm{CO}_{2}$ emissions was estimated by the following MIXED factor regression model:

$$
Y_{i j k l}=P_{k}\left(R_{l}\right)+B_{0}+B_{1} \mathrm{MuP}_{i j}+b_{0}+b_{1} \mathrm{MuP}_{i j}+e_{i j k l},
$$

where $y_{i j k l}$ is the dependent variable; $P(R), B_{0}$, and $B_{1} \mathrm{MuP}_{i j}$ are the fixed effects of period within an AMS robot unit, fixed intercept, and fixed effect of MuP; $b_{0}$ and $b_{1} \mathrm{MuP}_{i j}$ are random effects of $\mathrm{MuP}$; and $e_{i j k l}$ is the random residual effect $(i=1, \ldots, 96$ cows; $j=$ $1, \ldots, 10 \mathrm{~d} ; k=1, \ldots, 4$ periods; and $l=1,2$ robots). The cow(period) term was defined as SUBJECT; that is, the model evaluates relationships between $\mathrm{MuP}$ and gas emissions within each cow within 10-d period. The data was also analyzed by fixed factor regression analysis using each cow as an independent experimental unit. 


\section{RESULTS}

\section{Laboratory Study}

The average concentrations relative to a reference position (muzzle $=0 \mathrm{~cm}$ from the sampling point and in a horizontal position) for the sniffer method and recoveries for the flux method for each testing position are reported in Table 1 . The muzzle distance from the sampling point for the sniffer method was an important factor in determining the concentrations. When the muzzle was $10 \mathrm{~cm}$ from the sampling point, the relative concentrations decreased to $75 \%$ and were more variable $(\mathrm{CV}=23$ vs. $10 \%$ at $0 \mathrm{~cm})$. At a distance of $30 \mathrm{~cm}$ from the sampling inlet, the relative concentrations further decreased to $61 \pm 25 \%$. When wind was introduced to the sniffer method using a fan, the relative $\mathrm{CO}_{2}$ concentrations decreased to 13 to $33 \%$ of the reference depending on muzzle distance from the sampling inlet. The flux-method recovery ranged from 97 to $106 \%(\mathrm{CV}=2.6 \%)$ regardless of the position of the model cow head, head movement, or breath rate and was consistent throughout most recovery tests. Wind (6 $\mathrm{m} / \mathrm{s}$ ) was the only factor that clearly decreased the $\mathrm{CO}_{2}$ recovery of the flux method to about $85 \%$.

\section{Farm Studies}

Muzzle Position and Fluxes (Experiment 2). Fifty-nine cows completed the 4 study periods with acceptable muzzle-position data, and another 36 cows completed the 4 periods but had unacceptable muzzleposition data. Repeatability of muzzle position across the cows was 0.74 and 0.82 when analyzed using daily $(\mathrm{n}=40)$ or period $(\mathrm{n}=4)$ data for each cow, respectively. When the flux method data for all cows were not filtered according to muzzle position, fractional time with muzzle inside a manifold (i.e., from 0 to 1 ) and $\mathrm{CH}_{4}$ flux had a positive relationship $\left(\mathrm{R}^{2}=0.31\right.$; $P<0.001$; Figure 5). The relationship was weaker for changes in $\mathrm{CH}_{4}$ concentration measured by the sniffer method $\left(\mathrm{R}^{2}=0.07 ; P=0.012\right)$. For the unfiltered data of the 59 cows that had acceptable muzzle-position data, the relationship between muzzle position and $\mathrm{CH}_{4}$ flux was weaker $\left(\mathrm{R}^{2}=0.09 ; P=0.02\right)$ but the slope of the regression tended to be smaller (198 vs. 317; $P=0.09$ ). However, when the filtered data from the same 59 cows were analyzed, no significant relationship between muzzle position and $\mathrm{CH}_{4}$ flux $(P=0.80)$ or $\mathrm{CH}_{4}$ concentration $(P=0.78)$ was detected. The mean $\mathrm{CH}_{4}$ flux was lower (388 vs. $447 ; P<0.001 ; \mathrm{SE}=22$ ) for unfiltered than filtered data. When the data were filtered for muzzle position, the between-cow CV in $\mathrm{CH}_{4}$ flux decreased from 21.2 to $17.6 \%$.
The following relationships between $\mathrm{MuP}$, and fluxmethod $\mathrm{CH}_{4}$ fluxes or sniffer-method $\mathrm{CH}_{4}$ concentrations were determined from daily data using mixed model regressions:

$$
\begin{gathered}
\mathrm{CH}_{4} \text { flux }(\mathrm{g} / \mathrm{d})=177 \pm 11.5+306 \pm 13.0 \\
\times \operatorname{MuP}(P<0.001 ; \text { residual variance }=1,663), \\
\mathrm{CH}_{4} \text { concentration }(\mathrm{ppm})=625 \pm 28.6+140 \pm 29.2 \\
\times \operatorname{MuP}(P<0.001 ; \text { residual variance }=7,428) .
\end{gathered}
$$

The effect of muzzle position was significant $(P<$ 0.001) also on $\mathrm{CO}_{2}$ flux and $\mathrm{CO}_{2}$ concentration (data not shown). The $\mathrm{CH}_{4} / \mathrm{CO}_{2}$ ratio determined by the sniffer method was negatively $(P<0.001)$ related to muzzle position, but only a trend existed $(P=0.07)$ when determined by the flux method. The relationship between $\mathrm{CH}_{4}$ flux and $\mathrm{CO}_{2}$ flux and $\mathrm{BW}$ was weak $\left(\mathrm{R}^{2}\right.$ $=0.10, \mathrm{R}^{2}=0.13$ ) for the unfiltered flux-method data, but the relationships improved when the filtered data were used $\left(\mathrm{R}^{2}=0.32, \mathrm{R}^{2}=0.55\right)$.

Gas Emissions. In experiment 1, DMI did not differ between the flux- and sniffer-method periods (20.2 \pm 2.5 vs. $20.3 \pm 2.8 \mathrm{~kg} / \mathrm{d}$, respectively). In experiment 1 , the cows visited the concentrate feeding system on average $3.0 \pm 1.0$ and $2.7 \pm 0.9$ times per day during flux and sniffer periods, respectively. The average concentrate intake from the CF system was $0.8 \pm$ $0.31 \mathrm{~kg} / \mathrm{d}$. In experiment 2, estimated average intake of mixed ration was $18.6 \pm 4.6 \mathrm{~kg} / \mathrm{d}$, and the cows consumed on average $4.0 \pm 1.6 \mathrm{~kg} / \mathrm{d}$ of commercial concentrate pellet in the AMS. The cows visited the AMS $2.8 \pm 1.2$ times per day (range was 1 to 4 visits per day), which produced $2.0 \pm 0.7$ and $2.5 \pm 0.8$ visits per day of qualifying filtered gas data during flux and sniffer periods, respectively.

The fluxes and concentrations of $\mathrm{CH}_{4}$ and $\mathrm{CO}_{2}$ are shown in Table 2. Total $\mathrm{CH}_{4}$ flux was similar in both experiments, but $\mathrm{CO}_{2}$ flux was numerically greater in experiment 2. However, both $\mathrm{CH}_{4}$ and $\mathrm{CO}_{2}$ concentrations measured using the sniffer method were markedly smaller in experiment 2 compared with experiment 1. The between-cow $\mathrm{CV}$ of $\mathrm{CH}_{4}$ emissions was greater with the sniffer method compared with the flux method both in experiment 1 (17.6 vs. 11.0\%) and experiment 2 (28.0 vs. $17.6 \%)$. Similar differences were observed in between-cow $\mathrm{CV}$ of $\mathrm{CO}_{2}$ emissions (15.7 vs. $7.3 \%$ in experiment 1 and 29.3 vs. $15.7 \%$ in experiment 2 , respectively). However, between-cow $\mathrm{CV}$ values of the $\mathrm{CH}_{4} / \mathrm{CO}_{2}$ ratio for the flux and sniffer methods were rather similar (6.4 and $6.6 \%$ in experiment 1 and 8.8 vs. $7.5 \%$ in experiment 2 , respectively). The $\mathrm{CH}_{4} / \mathrm{CO}_{2}$ 


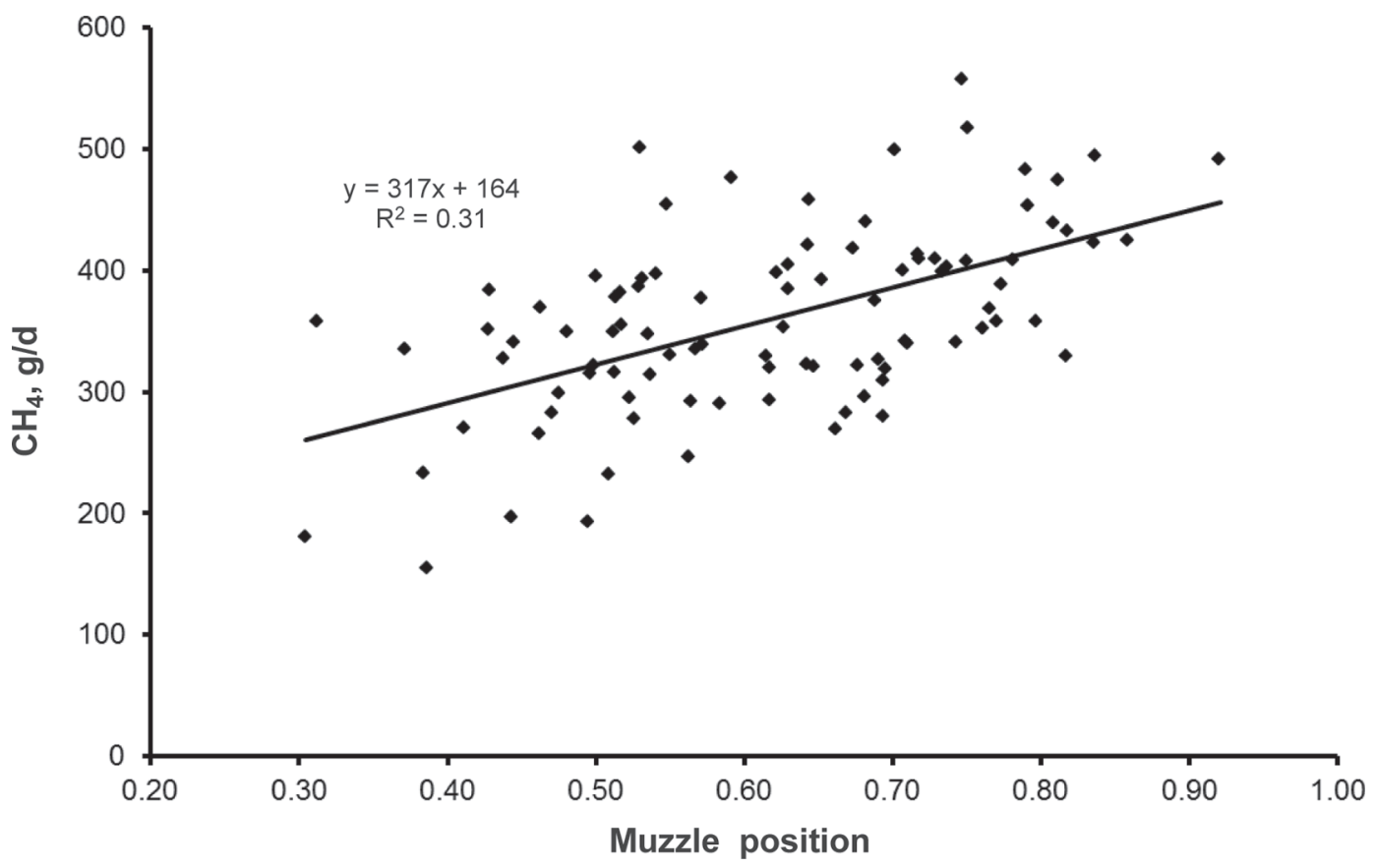

Figure 5. Relationship between the fraction of time (0-1) with muzzle in feed trough during milking (muzzle position) and $\mathrm{CH}_{4}$ emissions measured in the automatic milking system. Each point represents the averages of one cow during two 10-d flux-measurement periods.

ratio was significantly $(P=0.001)$ greater with the flux method compared with the sniffer method in experiment 1 , but the opposite was true in experiment 2 . In experiment $1, \mathrm{CH}_{4}$ and $\mathrm{CO}_{2}$ emissions determined by the flux method were significantly $(P<0.001)$ correlated to DMI, but the corresponding relationships were nonsignificant with the sniffer method (data not shown). Repeatability of gas measurements was generally high, and the values were similar between the experiments and methods (Table 2).

Relationships Between Gas Concentrations and Fluxes. The following relationships were estimated for $\mathrm{CH}_{4}$ concentrations (ppm) when measured by the sniffer method and $\mathrm{CH}_{4}$ flux measured with the flux method: experiment 1: $\mathrm{CH}_{4}$ flux $(\mathrm{g} / \mathrm{d})=360 \pm 60+0.070$

$$
\pm 0.0423 \times \text { sniffer } \mathrm{CH}_{4}\left[\mathrm{R}^{2}=0.09\right. \text {; }
$$

root mean square error $(\mathbf{R M S E})=47.1]$,

experiment 2: $\mathrm{CH}_{4}$ flux $(\mathrm{g} / \mathrm{d})=366 \pm 36+0.107$

$\pm 0.0455 \times$ sniffer $\mathrm{CH}_{4}\left(\mathrm{R}^{2}=0.09 ; \mathrm{RMSE}=69.8\right)$.

The relationship between the sniffer method $\mathrm{CH}_{4}$ concentration and $\mathrm{CH}_{4}$ flux was significant $(P=$ $0.02)$ in experiment 2 but not in experiment $1(P=$ 0.11). The intercept (i.e., observed $\mathrm{CH}_{4}$ flux at zero $\mathrm{CH}_{4}$ concentration measured with the sniffer method) was highly significant $(P<0.001)$ in both studies and

Table 2. Mean values, variability, and repeatability of $\mathrm{CH}_{4}$ and $\mathrm{CO}_{2}$ emissions in the farm conditions in dairy cows fed TMR (experiment 1 ) or mixed ration and concentrates (experiment 2)

\begin{tabular}{|c|c|c|c|c|c|c|c|c|}
\hline Item & \multicolumn{4}{|c|}{ Flux method ${ }^{1}$} & \multicolumn{4}{|c|}{ Sniffer method ${ }^{2}$} \\
\hline \multicolumn{9}{|l|}{ Experiment 1} \\
\hline $\mathrm{CO}_{2}$ & 75 & 11,619 & 850 & 0.84 & 57 & 14,924 & 2,340 & 0.87 \\
\hline $\mathrm{CH}_{4} / \mathrm{CO}_{2}, \mathrm{ppm} / \mathrm{ppm}$ & 75 & 0.107 & 0.0069 & 0.62 & 57 & 0.094 & 0.0062 & 0.57 \\
\hline \multicolumn{9}{|l|}{ Experiment 2} \\
\hline
\end{tabular}

${ }^{1}$ Units of measure are grams per day for the flux method.

${ }^{2}$ Units of measure are ppm for the sniffer method. 


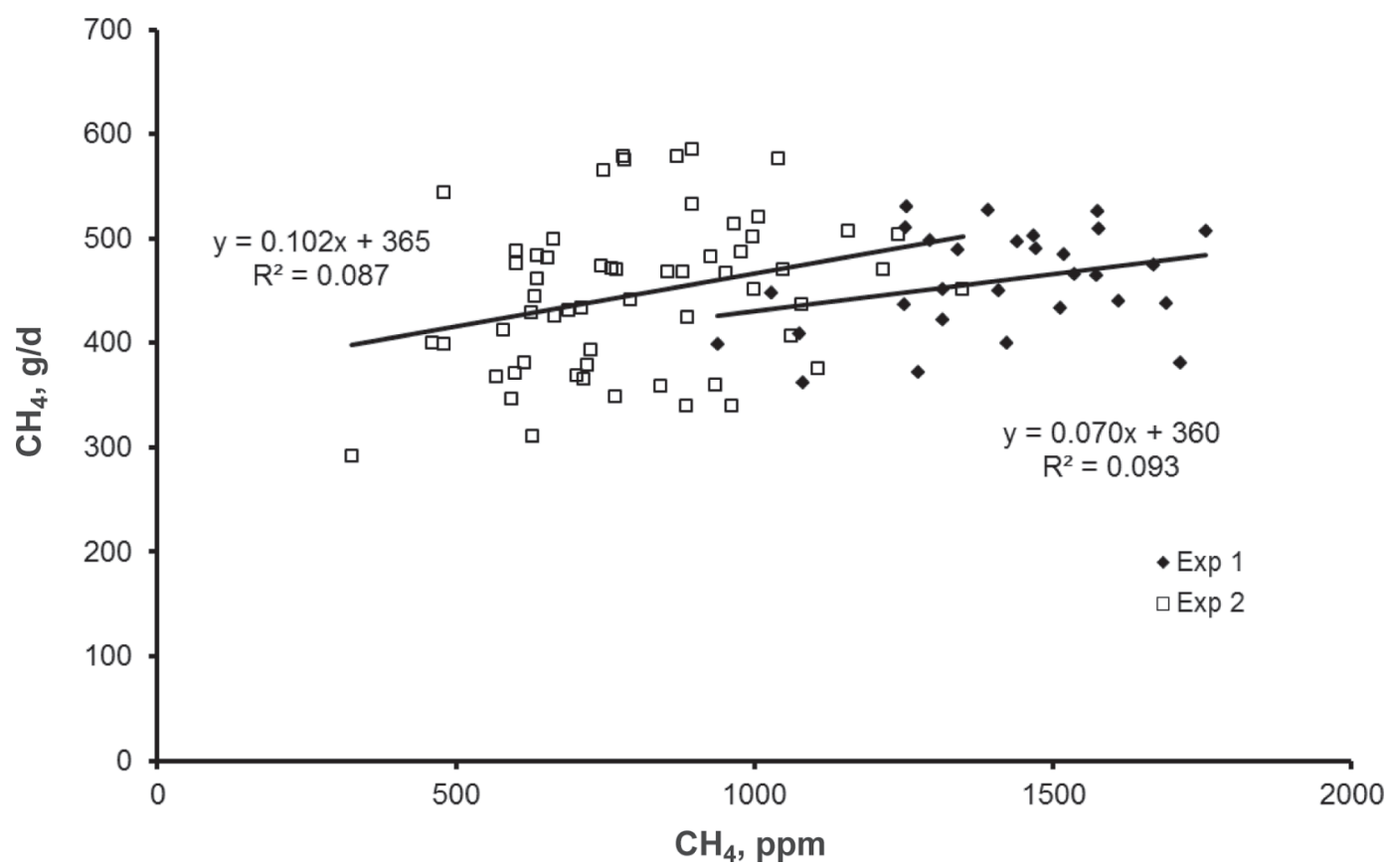

Figure 6. Relationship between the $\mathrm{CH}_{4}$ concentration (ppm) determined by the sniffer method and $\mathrm{CH}_{4}$ determined by the flux method $(\mathrm{g} / \mathrm{d})$. Exp = experiment.

represented approximately $80 \%$ of the observed mean $\mathrm{CH}_{4}$ flux (Figure 6). The effect of $\mathrm{CO}_{2}$ concentration on $\mathrm{CO}_{2}$ flux was not significant in either study (models not shown).

The predictions were improved when $\mathrm{CH}_{4} / \mathrm{CO}_{2}$ instead of $\mathrm{CH}_{4}$ concentration ratio was used as an independent variable in experiment1 but not in experiment 2 :

$$
\begin{aligned}
& \text { experiment 1: } \mathrm{CH}_{4} \text { flux }(\mathrm{g} / \mathrm{d})=94 \pm 129+3,874 \\
& \pm 1,369 \times \mathrm{CH}_{4} / \mathrm{CO}_{2}\left(\mathrm{R}^{2}=0.23 ; \mathrm{RMSE}=43.5\right)
\end{aligned}
$$

experiment 2: $\mathrm{CH}_{4}$ flux $(\mathrm{g} / \mathrm{d})=128 \pm 135+3,874$

$$
\pm 1,344 \times \mathrm{CH}_{4} / \mathrm{CO}_{2}\left(\mathrm{R}^{2}=0.09 ; \mathrm{RMSE}=69.8\right) .
$$

The linear effect of the $\mathrm{CH}_{4} / \mathrm{CO}_{2}$ ratio was significant in experiment 1 and in experiment $2(P=0.001 ; P=$ 0.02 , respectively; Figure 7 ). Intercepts were smaller and nonsignificant $(P>0.10)$ for both experiments. The $\mathrm{R}^{2}$ values increased to 0.25 and 0.18 when both $\mathrm{CH}_{4}$ concentration and $\mathrm{CH}_{4} / \mathrm{CO}_{2}$ ratio were used as independent variables to predict $\mathrm{CH}_{4}$ flux. The relationship between $\mathrm{CH}_{4} / \mathrm{CO}_{2}$ ratios determined by the sniffer and flux methods was statistically significant $(P$ $<0.01$ ) in both studies, but $\mathrm{R}^{2}$ values were relatively low and slopes were significantly below 1.0 (Figure 8). In experiment 1 the $\mathrm{CH}_{4} / \mathrm{CO}_{2}$ ratio was positively ( $P$ $<0.001$ ) related to $\mathrm{CH}_{4}$ emissions per kilogram of DMI when measured by the flux method but not when measured using the sniffer method $(P=0.17)$.

\section{DISCUSSION}

The current study is the first directly comparing spot-sampling methods based on breath analysis called the sniffer method and the flux method. Comparison of the methods presents some problems, because simultaneous measurements with the same cows may not always be possible. In the present study switch-back designs with 5 (experiment 1) or 4 (experiment 2) periods were used to minimize random period or diet effects. In experiment 1 mean DMI and milk yield during the flux periods were strongly correlated with the corresponding values during the sniffer periods $\left(R^{2}=0.90\right.$ and 0.97 , respectively). Accuracy and precision of the methods can be assessed on the basis of variability and repeatability; relationships between observed $\mathrm{CH}_{4}$ variables and variables known to be related to quantitative $\mathrm{CH}_{4}$ emissions (e.g., DMI, BW); and discussion on how well observed emissions compare with those predicted from models derived from respiration-chamber studies. The results of the present study indicate that the flux method was able to provide realistic and accurate gasflux data. In experiment $1, \mathrm{CH}_{4}$ fluxes were $6.7 \%$ of gross energy intake assuming gross energy concentration of $18.5 \mathrm{MJ} / \mathrm{kg}$ of $\mathrm{DM}$, which agrees well with the data of Yan et al. $(2000,2010)$ for cattle fed mainly 

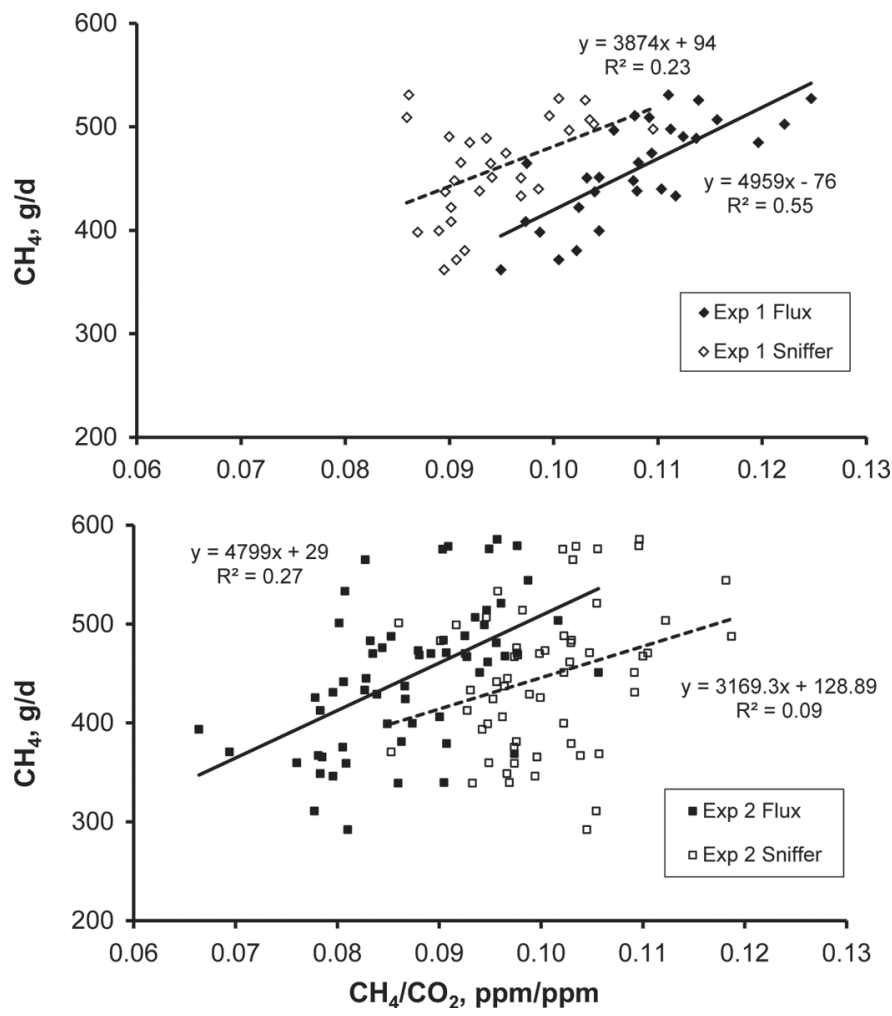

Figure 7. Relationships between the $\mathrm{CH}_{4} / \mathrm{CO}_{2}$ determined by the flux or sniffer method and $\mathrm{CH}_{4}$ flux determined by the flux method in 2 experiments (Exp).

grass silage-based diets. Similarly, average herd $\mathrm{CH}_{4}$ flux was $5.8 \%$ of gross energy intake in experiment 2 . Lower value in experiment 2 than experiment 1 can be attributed to greater DMI and different diet composition in experiment 2 (corn silage vs. grass silage, corn vs. barley grain). Significant correlations were found between DMI and the flux method $\mathrm{CH}_{4}$ in experiment 1 and between $\mathrm{BW}$ and $\mathrm{CH}_{4}$ and $\mathrm{CO}_{2}$ fluxes in experiment 2. Hammond et al. (2013) demonstrated in direct comparisons a good agreement between the flux method and respiration chambers, but emissions were $12 \%$ lower with the flux method compared with $\mathrm{SF}_{6}$. Waghorn et al. (2013) found spot flux measurements of $\mathrm{CH}_{4}$ to correlate well with calculated $\mathrm{CH}_{4}$ emissions on an individual-cow basis.

\section{Characteristics of Ruminant Animal Breath}

The physical injection of a ruminant animal's eructation and tidal breath into room air is complex. Tidal breath occurs as a discontinuous flow, one breath every few seconds, whereas eructation of rumen gas is injected into the exhalation stream at intervals of 40 to $60 \mathrm{~s}$ (Van Soest, 1994). Given the differences in release timing, release point, and gas densities, it is unlikely

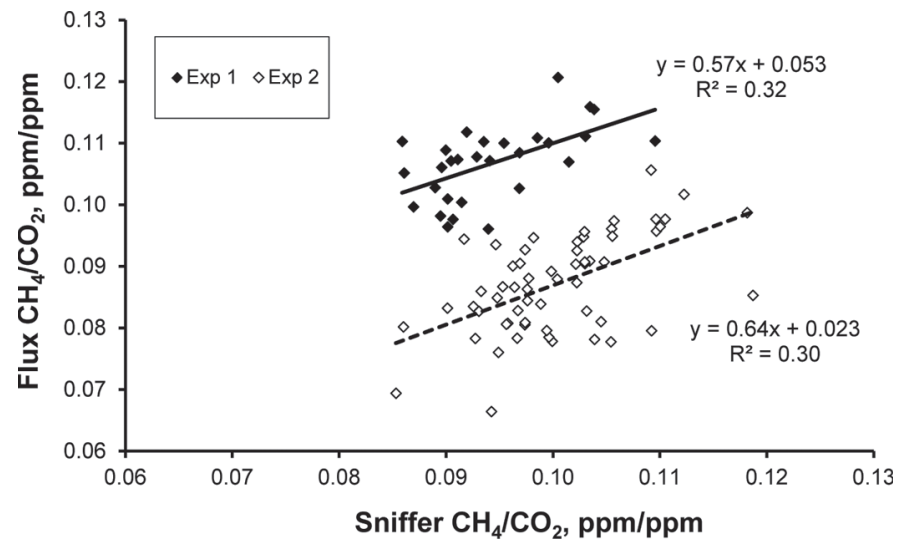

Figure 8. Relationship between $\mathrm{CH}_{4} / \mathrm{CO}_{2}$ ratios estimated by the sniffer and flux methods. Exp $=$ experiment.

that the eructation cloud and tidal-breath cloud become uniformly mixed. Other factors such as muzzle movement and position relative to the feed trough, breathing patterns, room air densities, and external air currents will also have a significant effect on dilution and resulting $\mathrm{CH}_{4}$ and $\mathrm{CO}_{2}$ concentrations. It was demonstrated that small differences in sampling location can determine whether background room air or injected air would be measured and that obstructions can affect airflow and contaminant transport (Posner et al., 2003). It is difficult to determine the ideal position of a sampling inlet with the discontinuous and highly variable flows (Nielsen, 1998). In contrast, with the flux method, a large airflow rate induced into the feed trough creates a flow field that captures the emitted gases for quantitative measurements of total volume (flow) and gas concentrations.

\section{Laboratory Study}

Although the laboratory study was not completely representative of a real farm environment and the model cow head has limitations because it does not exactly mimic the complex physical processes of gas release from a cow, it does allow for precise control of relevant variables (such as head position and breathing) that could affect the 2 measurement methods that would not be possible on farm. It is also expected that because $\mathrm{CH}_{4}$ emissions are released as eructation pulses, the variability in the $\mathrm{CH}_{4}$ measurements would be greater than for the constant release of $\mathrm{CO}_{2}$ from the model cow head. In contrast to the flux method, relative gas concentrations determined by the sniffer method were much more variable and were influenced by small changes in the muzzle position relative to the sampling inlet. With increased muzzle distance it is expected that the tidal breath will be more di- 
luted before reaching the sampling inlet. Muzzle positions farther than $30 \mathrm{~cm}$ from the sampling inlet were not tested, but at some distance, even with the flux method, the muzzle will become outside the capturing flow space, which would affect the measurements. It is worth noting that the $\mathrm{CV}(12 \%)$ with 0 -cm muzzle distance is greater than typical between-animal CV of $\mathrm{CH}_{4}$ emissions in respiration-chamber studies (7-8\%) in animals fed at the same level of feed intake (Blaxter and Clapperton, 1965). With muzzle distances of 10 to $30 \mathrm{~cm}$, the CV (24-26\%) was markedly greater than the between-animal $\mathrm{CV}$ of $\mathrm{CH}_{4}$ flux in the current field study or in a data set from respiration studies (CV $=17 \%$ ) covering wide ranges both in cow and feed variables (Yan et al., 2010).

\section{Variability and Repeatability in Farm Studies}

Overall, the between-cow CV was greater with the sniffer method compared with the flux method in both on-farm studies (Table 2) and consistent with the greater CV with the sniffer method in the laboratory study (Table 1). The smaller variability of flux method and sniffer method in experiment 1 compared with experiment 2 could be attributed to a more uniform group of cows (DMI, DIM, milk yield) used in experiment 1 . Higher CV with sniffer method in experiment 2 could also result from differences in feed-trough geometry and head movement. In experiment 1 , the variability of sniffer method $\mathrm{CH}_{4}$ and $\mathrm{CO}_{2}$ concentrations was smaller than the corresponding values (25.6 and $29.8 \%$ ) reported by de Haas et al. (2013). However, in experiment 2 the variability of the $\mathrm{CH}_{4}$ concentration using the sniffer method was similar to the values reported by de Haas et al. (2013). Garnsworthy et al. (2012) reported considerable variability between cows for their $\mathrm{CH}_{4}$ emission index ( $\mathrm{mg}$ of $\left.\mathrm{CH}_{4} / \mathrm{min}\right)$ during milking $(\mathrm{CV}=33 \%)$. In a recent on-farm study, between-cow $\mathrm{CV}$ of $\mathrm{CH}_{4}$ emission index varied from 22 to $67 \%$ among cows within a farm (Bell et al., 2014a). The average sniffer-method $\mathrm{CH}_{4}$ was almost 2-fold higher in experiment 1 compared with experiment 2 in the present study despite similar flux method- $\mathrm{CH}_{4}$ data. In a study comparing sniffer-method $\mathrm{CH}_{4}$ between farms, a 6-fold range in $\mathrm{CH}_{4}$ emission index was found between the lowest and highest farms (Bell et al., 2014a), indicating difficulties in harmonization of the sniffer method across farms. The between-cow variability using the sniffer method (Garnsworthy et al., 2012; de Haas et al., 2013; Bell et al., 2014a; present study) was much higher than in the data set $(\mathrm{n}=579$ cows $)$ from respiration studies (Yan et al., 2010) despite large variability in diet and cow variables $(\mathrm{BW}=379-733$ $\mathrm{kg}$; DMI $=7.5-25.0 \mathrm{~kg} / \mathrm{d}$; and forage proportion $=$
$18-100 \%$ of diet DM) in the latter. These data suggest that the sniffer method results in greater between-cow differences in $\mathrm{CH}_{4}$ emissions than observed in chamber studies. Only in experiment 1 between-cow CV with the sniffer method was similar to Yan et al. (2010) data, but the variability in DMI, BW, milk yield, and especially in diet composition was much smaller in the present study. Theoretically, the CV of the concentration of $\mathrm{CH}_{4}$ should not be greater than in the flux of $\mathrm{CH}_{4}$ provided that determined concentrations using the sniffer method are accurate. Flux is calculated as concentration multiplied by airflow, and airflow must be assumed to be rather consistent between cows. Possible random variation in airflow rates resulting from varied flow conditions would result in greater CV of the flux compared with the concentrations.

Repeatability values $(0.72-0.74)$ for total $\mathrm{CH}_{4}$ flux in the current study and 2 earlier studies (Huhtanen et al., 2013) using the same flux method were greater than those reported by Vlaming et al. (2007) for the $\mathrm{SF}_{6}$ technique. In the present study, the repeatability values for $\mathrm{CH}_{4} / \mathrm{CO}_{2}$ ratios with the flux system were similar to those reported earlier by Huhtanen et al. (2013) for the same system but markedly greater with the sniffer system than the values of approximately 0.35 reported by Lassen et al. (2012). Negussie et al. (2013) reported a repeatability value of 0.36 in $\mathrm{CF}$ for calculated $\mathrm{CH}_{4}$ emissions using the Madsen et al. (2010) method based on $\mathrm{CH}_{4} / \mathrm{CO}_{2}$ ratio and estimated $\mathrm{CO}_{2}$ production. This value is low considering that variables for calculating $\mathrm{CO}_{2}$ production (ECM and $\mathrm{BW}$ ) are highly repeatable, for example 0.90 and 0.97 in experiment 1 , respectively.

Repeatability values of the sniffer method, both with $\mathrm{CH}_{4}$ concentrations and $\mathrm{CH}_{4} / \mathrm{CO}_{2}$ ratios, were of the same magnitude as for the flux method. This may partly be due to greater variability of the sniffer data. High repeatability does not necessarily indicate that the data are accurate. Repeatability of $\mathrm{CH}_{4}$ flux was high (0.84) when the data from AMS were not filtered according to muzzle position, but the between-cow variability was also much greater. This could partly reflect the wider range in the data due to the effects of muzzle position and the high (0.82) repeatability of muzzle-position behavior for individual cows.

\section{Predicting $\mathrm{CH}_{4}$ Flux from $\mathrm{CH}_{4}$ Concentration}

Accurate ranking of the cows for $\mathrm{CH}_{4}$ emissions does not necessarily need accurate measurements, but the measured values need to be correlated with actual values. In contrast to observations of Garnsworthy et al. (2012), who found a good relationship between $\mathrm{CH}_{4}$ emission rates measured during milking on-farm and in respiration chambers, the relationship between $\mathrm{CH}_{4}$ 
concentrations measured by the sniffer method and $\mathrm{CH}_{4}$ flux was weak in both on-farm experiments of the present study. Emissions of $\mathrm{CH}_{4}$ and $\mathrm{CO}_{2}$ determined using the flux method were strongly $(P<0.001)$ related to $\mathrm{DMI}$ in experiment 1 (or to $\mathrm{BW}$ in experiment 2 ), which could be expected because intake is the main driver of enteric $\mathrm{CH}_{4}$ emissions (Yan et al. 2000; Ramin and Huhtanen, 2013). However, no significant relationship existed between DMI and sniffer-method $\mathrm{CH}_{4}$ or $\mathrm{CO}_{2}$ concentrations in experiment 1 , and a weak relationship existed between sniffer-method $\mathrm{CH}_{4}$ and $\mathrm{BW}\left(\mathrm{R}^{2}\right.$ $=0.04$ ) in experiment 2 . In the study by Garnsworthy et al. (2012), increased DMI was associated with only minor quantitative increases in $\mathrm{CH}_{4}$ emission rate. In a recent study by Bell et al. (2014b), $\mathrm{CO}_{2}$ concentration measured using the sniffer method was not related to $\mathrm{CO}_{2}$ production estimated according to Madsen et al. (2010). In contrast, in the data from respirationchamber studies (Hellwing et al., 2013), predicted and observed $\mathrm{CO}_{2}$ production were significantly correlated $\left(\mathrm{R}^{2}=0.55\right)$. In agreement with Garnsworthy et al. (2012) in direct chamber comparison, variability was much greater for $\mathrm{CH}_{4}$ concentrations than for $\mathrm{CH}_{4}$ flux. In both the study by Garnsworthy et al. (2012) and the present study the intercepts of regressions predicting fluxes from $\mathrm{CH}_{4}$ concentrations were highly positive; that is, high predicted emissions at zero $\mathrm{CH}_{4}$ concentrations. It seems that even in the $\mathrm{CF}$, with a smaller feed trough and more controlled muzzle position, dilution of exhaled gases can be inconsistent as measured with the sniffer method, probably because small 3-dimensional differences in muzzle position and differences in mixing patterns can create large difference in concentrations (Nielsen, 1998). Filtering $\mathrm{CH}_{4}$ concentrations for the muzzle position for the sniffer method did not improve the predictions of $\mathrm{CH}_{4}$ fluxes. It could be speculated that accuracy and statistical confidence of the sniffer method could be improved by increasing the number of observations per cow, but the high ( 0.74 for daily observations) repeatability of muzzle position suggests that there can be systematic differences in the dilution of exhaled gases due to consistent muzzle movement behavior of the cows.

\section{Estimation of $\mathrm{CH}_{4}$ Flux from the $\mathrm{CO}_{2} / \mathrm{CH}_{4}$ Ratio}

In the present study predictions of enteric $\mathrm{CH}_{4}$ emissions by the sniffer method $\mathrm{CH}_{4}$ concentrations were inadequate. The better relationship between the $\mathrm{CH}_{4}$ / $\mathrm{CO}_{2}$ ratios and $\mathrm{CH}_{4}$ fluxes than the corresponding relationship between $\mathrm{CH}_{4}$ concentrations and fluxes suggests that $\mathrm{CH}_{4} / \mathrm{CO}_{2}$ ratios could be more useful in ranking of the cows than the $\mathrm{CH}_{4}$ concentration. However, interpretation of the data would be more difficult.
This is because, in addition to true differences in $\mathrm{CH}_{4}$ emissions, the level of feed intake, efficiency of energy utilizations, and body energy balance also influence the gas ratio. Variability of the $\mathrm{CH}_{4} / \mathrm{CO}_{2}$ ratio was relatively small $(\mathrm{CV}=6-8 \%)$ in the present study with both sniffer and flux methods and in earlier studies using the same flux method (Huhtanen et al., 2013). In a respiration-chamber data set $(\mathrm{n}=157)$ covering a wide range of diets, the $\mathrm{CV}$ of the $\mathrm{CH}_{4} / \mathrm{CO}_{2}$ ratio was 9.5\% (Hellwing et al., 2013). Variability of the $\mathrm{CH}_{4} /$ $\mathrm{CO}_{2}$ ratio was much smaller $(\mathrm{CV}=4.8 \%, \mathrm{n}=100)$ when the cows were fed the same diet in a respirationchamber study (A. R. Bayat and K. J. Shingfield, MTT-Agrifood Research Finland, Jokioinen, Finland, personal communication). In contrast, much greater variability in $\mathrm{CH}_{4} / \mathrm{CO}_{2}$ ratios (15-20\%) with the sniffer method was reported in previous studies (Lassen et al., 2012; Lassen and Løvendahl, 2013; Haque et al., 2014) than with the sniffer method in this study. In the study by Lassen et al. (2012), the values of the $\mathrm{CH}_{4}$ / $\mathrm{CO}_{2}$ ratios were $30 \%$ greater for Holstein cows compared with Jersey cows. This is unexpected considering small between-cow variation in the gas ratios observed in studies with respiration chambers or in the current flux-method results. Variability of the $\mathrm{CH}_{4} / \mathrm{CO}_{2}$ ratios was clearly smaller than that of $\mathrm{CH}_{4}$ flux in experiment 1 and experiment 2 and not consistently different between the methods. Even though the between-cow $\mathrm{CV}$ of the $\mathrm{CH}_{4} / \mathrm{CO}_{2}$ ratio was small and repeatability rather high, the values of the $\mathrm{CH}_{4} / \mathrm{CO}_{2}$ ratios determined by the sniffer and the flux method were only moderately correlated, probably related to greater random variation in gas concentrations measured by the sniffer method. The relationship between the $\mathrm{CH}_{4} / \mathrm{CO}_{2}$ ratio and $\mathrm{CH}_{4}$ flux was weaker when the $\mathrm{CH}_{4} / \mathrm{CO}_{2}$ ratio was determined by the sniffer method than by the flux method. Furthermore, the $\mathrm{CH}_{4} / \mathrm{CO}_{2}$ ratios had opposite highly significant differences between the methods in experiment 1 and experiment 2 (flux $>$ sniffer in experiment 1 ; flux $<$ sniffer in experiment 2 ). Because of the high repeatability of $\mathrm{CH}_{4} / \mathrm{CO}_{2}$ ratios and $\mathrm{CH}_{4}$ fluxes between sampling intervals, it is unlikely these differences are due to different time of measurements and more likely suggests that the size and or geometry of the feed through might influence dilution and or mixing of $\mathrm{CH}_{4}$ and $\mathrm{CO}_{2}$ gases and effect on resulting ratios. The significant effect of muzzle position on $\mathrm{CH}_{4}$ / $\mathrm{CO}_{2}$ ratios determined by the sniffer is in line with this suggestion.

Predicting $\mathrm{CH}_{4}$ flux from the measured $\mathrm{CH}_{4} / \mathrm{CO}_{2}$ ratio using estimated $\mathrm{CO}_{2}$ as tracer, as described by Madsen et al. (2010), can have some advantages compared with the methods based only on concentration measurements. In the present study (experiment 1$) R^{2}$ 
improved from 0.09 with $\mathrm{CH}_{4} / \mathrm{CO}_{2}$ to 0.24 when the Madsen et al. (2010) tracer method was used to predict $\mathrm{CH}_{4}$ flux. Because the estimated $\mathrm{CO}_{2}$ production is a direct function of heat production, it can be expected to be related to ME (or DM) intake. Therefore, predicted values of $\mathrm{CH}_{4}$ emissions will automatically be correlated to observed $\mathrm{CH}_{4}$ emissions.

Hellwing et al. (2013) evaluated the Madsen et al. (2010) method using a data set from respirationchamber studies $(\mathrm{n}=157)$ and found a reasonably good relationship $\left(\mathrm{R}^{2}=0.55\right)$ between predicted and observed $\mathrm{CH}_{4}$ emissions. However, $\mathrm{CH}_{4}$ emissions were underestimated on average by $17 \%$. The residuals were significantly related to observed $\mathrm{CH}_{4}$ emission and ECM yield. The $\mathrm{CH}_{4} / \mathrm{CO}_{2}$ ratio was determined by the respiration-chamber method, i.e., the unexplained variation was related to errors in the estimates of $\mathrm{CO}_{2}$ production. The performance of the $\mathrm{CO}_{2}$ tracer gas model is likely to be lower when the gas ratio is based on the sniffer method. In the present study (experiment 1) predictions were more precise $\left(R^{2}=0.24\right.$ vs. 0.47$)$ and accurate (mean bias 45 vs. $-7 \mathrm{~g} / \mathrm{d}$ ) when the $\mathrm{CH}_{4}$ / $\mathrm{CO}_{2}$ ratio was determined by the flux rather than the sniffer method. The inferior precision of the predictions of $\mathrm{CH}_{4}$ emissions from $\mathrm{CH}_{4} / \mathrm{CO}_{2}$ ratios determined by the sniffer method as compared with the flux method in the current study supports this suggestion. The opposite ranking and significant differences between the flux and sniffer method suggest that different geometry of feed through in experiment 1 and experiment 2 can influence the separation of $\mathrm{CH}_{4}$ and $\mathrm{CO}_{2}$ before sampling.

The Madsen et al. (2010) method to calculate heat production basically assumes that the efficiency of use of $\mathrm{ME}$ for maintenance and production is constant among cows. However, between-cow CV in fasting heat production was on average $7.6 \%$ for groups of 6 to 9 cows (Flatt and Coppock, 1963; Yan et al., 1997; Birnie et al., 2000), indicating between-cow differences in basal metabolism. Variation in BCS can cause large bias in estimating maintenance requirements from $\mathrm{BW}$ (Birnie et al., 2000). Published data also show rather large variation in the efficiency of $\mathrm{ME}$ use for milk production above maintenance (Agnew et al., 1998; Agnew and Yan, 2000). When estimated for cows with ME intake above maintenance exceeding 1.0 MJ of ME $/ \mathrm{kg}$ of $\mathrm{BW}^{0.75}$ as reported by Agnew et al. (1998), the CV of $\mathrm{ME}$ use was approximately $10 \%$. Improved efficiency at a fixed level of feed intake decreases $\mathrm{CO}_{2}$ emissions, thereby increasing the $\mathrm{CH}_{4} / \mathrm{CO}_{2}$ ratio. On the other hand, improved efficiency increases milk production and, consequently, the estimated $\mathrm{CO}_{2}$ production. Consequently, $\mathrm{CH}_{4}$ emissions will be overestimated, partly because of true increases in the $\mathrm{CH}_{4} / \mathrm{CO}_{2}$ ratio and partly because of the overestimation of $\mathrm{CO}_{2}$ production with improved feed efficiency.

\section{CONCLUSIONS}

Novel spot-sampling methods to measure $\mathrm{CH}_{4}$ under in vivo conditions in addition to traditional respiratory chambers (standard) are available for research purposes in cattle. The present results suggest that measurements of $\mathrm{CH}_{4}$ and $\mathrm{CO}_{2}$ gas concentrations from exhaled air using the sniffer method may not reliably rank individual-cow emissions within a herd. Concentrations of $\mathrm{CH}_{4}$ and $\mathrm{CO}_{2}$ determined by the sniffer method were poorly correlated with respective gas fluxes, and only weak relationships between gas concentrations and any other biological parameters such as DMI or BW were observed. It is possible that sniffer-method gas concentrations partly reflect muzzle movement, and muzzle proximity to the sample intake, and variable air-mixing conditions within the feed trough. These factors may explain the higher between-cow variation in enteric $\mathrm{CH}_{4}$ emissions measured using the sniffer method compared with the flux method or to data from respiration-chamber studies. Increasing the number of replicates may not improve the accuracy of the sniffer method, because the muzzle position had a high repeatability and strong influence on measured gas emissions. It is concluded that in farm conditions, to accurately measure fluxes, an induced airflow system to control the mixing and muzzle-position sensor are required.

\section{ACKNOWLEDGMENTS}

This study was partially funded by a grant from the W. K. Kellogg Foundation to Michigan State University Kellogg Biological Station and support by the USDA National Institute of Food and Agriculture [NE1044/ Utsumi], project [MICL04069], to Santiago Utsumi. Pekka Huhtanen and Edward Cabezas-Garcia gratefully acknowledge the support from the Swedish University of Agricultural Sciences and technical help from Viktor Brodin. The authors also acknowledge technical assistance from Paul Greenway and Kellogg Biological Station dairy farm staff.

\section{REFERENCES}

Agnew, R. E., T. Yan, and F. J. Gordon. 1998. Nutrition of the high genetic merit dairy cow-Energy metabolism studies. Pages 181208 in Recent Advances in Animal Nutrition. P. C. Garnsworthy and J. Wiseman, ed. Nottingham Univ. Press, Nottingham, UK.

Agnew, R. E., and T. Yan. 2000. Impact of recent research on feeding systems of dairy cattle. Livest. Prod. Sci. 66:197-215.

Bell, M. J., S. L. Potterton, J. Craigon, N. Saunders, R. H. Wilcox, M. Hunter, J. R. Goodman, and P. C. Garnsworthy. 2014a. Variation 
in enteric methane emissions among cows on commercial dairy farms. Animal 8:1540-1546.

Bell, M. J., N. Saunders, R. H. Wilcox, E. M. Homer, J. R. Goodman, J. Craigon, and P. C. Garnsworthy. 2014b. Methane emissions among individual dairy cows during milking quantified by eructation peaks or ratio with carbon dioxide. J. Dairy Sci. 97:65366546.

Birnie, J. W., R. E. Agnew, and F. J. Gordon. 2000. The influence of body condition on the fasting energy metabolism of nonpregnant, nonlactating dairy cows. J. Dairy Sci. 83:1217-1223.

Blaxter, K. L., and J. L. Clapperton. 1965. Prediction of the amount of methane produced by ruminants. Br. J. Nutr. 19:511-522.

de Haas, Y., J. W. van Riel, R. F. Veerkamp, W. Liansun, and N. Ogink. 2013. On-farm methane measurements in exhaled air of individual Dutch cows obtained during milking using Fourier transformed infrared methods. Adv. Anim. Biosci. 4:391.

Flatt, W. G., and C. E. Coppock. 1963. Fasting metabolism of dry, nonpregnant adult dairy cows. J. Dairy Sci. 46:638.

Garnsworthy, P. C., J. Craigon, J. H. Hernandez-Medrano, and N. Saunders. 2012. On-farm methane measurements during milking correlate with total methane production by individual dairy cows. J. Dairy Sci. 95:3166-3180.

Grainger, C., T. Clarke, S. M. McGinn, M. J. Auldist, K. A. Beauchemin, M. C. Hannah, G. C. Waghorn, H. Clark, and R. J. Eckard. 2007. Methane emissions from dairy cows measured using the sulfur hexafluoride (SF6) tracer and chamber techniques. J. Dairy Sci. 90:2755-2766.

Hammond, K., D. J. Humphries, L. A. Crompton, P. Kirton, C. Green, and C. K. Reynolds. 2013. Methane (GreenFeed) compared emissions from growing dairy heifers estimated using an automated head chamber to respiration chambers or $\mathrm{SF}_{6}$ techniques. Adv. Anim. Biosci. 4:447.

Haque, M. N., C. Cornou, and J. Madsen. 2014. Estimation of methane emission using the $\mathrm{CO} 2$ method from dairy cows fed concentrate with different carbohydrate compositions in automatic milking system. Livest. Sci. 164:56-67.

Hegarty, R. S. 2013. Applicability of short-term emission measurements for on-farm quantification of enteric methane. Animal 7:401-408.

Hegarty, R. S., D. Alcock, D. L. Robinson, J. P. Goopy, and P. E. Vercoe. 2010. Nutritional and flock management options to reduce methane output and methane per unit product from sheep enterprises. Anim. Prod. Sci. 50:1026-1033.

Hellwing, A. L., P. Lund, M. R. Weisbjerg, M. Brask, and T. Hvelplund. 2012. Technical note: Test of a low-cost and animal-friendly system for measuring methane emissions from dairy cows. J. Dairy Sci. 95:6077-6085.

Hellwing, A. L. F., P. Lund, J. Madsen, and M. R. Weisberg. 2013. Comparison of enteric methane production predicted from the $\mathrm{CH} 4 / \mathrm{CO} 2$ ratio and measured in respiration chambers. Adv. Anim. Biosci. 4:557.

Huhtanen, P., S. J. Krizsan, M. Hetta, H. Gidlund, and E. H. Cabezas Garcia. 2013. Repeatability and between cow variability of enteric CH4 and total CO2 emissions. Adv. Anim. Biosci. 4:588.

IPCC (International Panel on Climate Change). 2006. Revised IPCC Guidelines for National Greenhouse Gas Inventories. Chapter 10 Vol. 4: Agriculture, Forestry and Other Land Use. Accessed Feb. 17, 2014. http://www.ipcc-nggip.iges.or.jp/public/2006gl/vol4 htm.

Johnson, K. A., M. Huyler, H. Westberg, B. Lamb, and P. Zimmerman. 1994. Measurement of methane emissions from ruminant livestock using a sulphur hexafluoride tracer technique. Environ. Sci. Technol. 28:359-362.
Lassen, J., and P. Løvendahl. 2013. Heritability for enteric methane emission from Danish Holstein cows using a non-invasive FTIR method. Adv. Anim. Biosci. 4:280.

Lassen, J., P. Løvendahl, and J. Madsen. 2012. Accuracy of noninvasive breath methane measurements using Fourier transform infrared methods on individual cows. J. Dairy Sci. 95:890-898.

Madsen, J., B. S. Bjerg, T. Hvelplund, M. R. Weisbjerg, and P. Lund. 2010. Methane and carbon dioxide ratio in excreted air for quantification of methane production in ruminants. Livest. Sci. 129:223-227.

McLean, J. A., and G. Tobin. 1987. Animal and Human Calorimetry. Cambridge Univ. Press, New York, NY.

Negussie, E., A. E. Liinamo, P. Mäntysaari, E. A. Mäntysaari, and M. H. Lidauer. 2013. Measurement of methane in dairy cows via photoacoustic infrared spectroscopy technique: Sources of variation in daily methane output. Adv. Anim. Biosci. 4:463.

Nielsen, P. V. 1998. The Selection of Turbulence Models for Prediction of Room Airflow. No. 86, Vol. R9828. Dept. Build. Technol. Struct. Eng. Indoor Environ. Eng., Aalborg, Denmark.

Pinares-Patiño, C. S. S. M. Hickey, E. A. Young, K. G. Dodds, S. MacLean, G. Molano, E. Sandoval, H. Kjestrup, R. Harland, C. Hunt, N. K. Pickering, and J. C. McEwan. 2013. Heritability estimates of methane emissions from sheep. Animal 7:316-321.

Pinares-Patiño, C. S., K. R. Lassey, R. J. Martin, G. Molano, M. Ferandez, S. MacLean, E. Sandoval, D. Luo, and H. Clark. 2011. Assessment of the sulphur hexafluoride (SF6) tracer technique using respiration chambers for estimation of methane emissions from sheep. Anim. Feed Sci. Technol. 166-167:201-209.

Posner, J. D., C. R. Buchanan, and D. Dunn-Rankin. 2003. Measurement and prediction of indoor air flow in a modem room. Energy Build. 35:515-526.

Ramin, M., and P. Huhtanen. 2013. Development of equations for predicting methane emissions from ruminants. J. Dairy Sci. 96:2476-2493.

SAS Institute. 2008. SAS/STAT Software, Release 9.2. SAS Inst. Inc., Cary, NC.

Stevens, D. G. 1981. A model of respiratory vapor losses in Holstein dairy cattle. Trans. ASEA 24:151-158.

Van Soest, P. J. 1994. Nutritional Ecology of the Ruminant. Cornell Univ. Press, Ithaca, NY.

Vlaming, J. B., I. M. Brookes, S. O. Hoskin, C. S. Pinares-Patiño, and H. Clark. 2007. The possible influence of intra-ruminal sulphur hexafluoride release rates on calculated methane emissions from cattle. Can. J. Anim. Sci. 87:269-275.

Waghorn, G., E. J. Garnet, C. S. Pinares, and S. Zimmerman. 2013. Implementation of GreenFeed for estimating methane in a dairy herd grazing pasture. Adv. Anim. Biosci. 4:436.

Yan, T., F. J. Gordon, C. P. Ferris, R. E. Agnew, M. G. Porter, and D. C. Patterson. 1997. The fasting heat production and effect of lactation on energy utilisation by dairy cows offered forage-based diets. Livest. Prod. Sci. 52:177-186.

Yan, T., R. E. Agnew, F. J. Gordon, and M. G. Porter. 2000. Prediction of methane energy output in dairy and beef cattle offered grass silage-based diets. Livest. Prod. Sci. 64:253-263.

Yan, T., C. S. Mayne, F. G. Gordon, M. G. Porter, R. E. Agnew, D. C. Patterson, C. P. Ferris, and D. J. Kilpatrick. 2010. Mitigation of enteric methane emissions through improving efficiency of energy utilization and productivity in lactating dairy cows. J. Dairy Sci. 93:2630-2638.

Zimmerman, S., A. Brito, P. Huhtanen, K. Johnson, J. Michal, A. Pereira, C. Pineras, S. Utsumi, G. Waghorn, and P. Zimmerman 2013. Measurement and evaluation of enteric $\mathrm{CH} 4$ emissions and variability in production systems. Adv. Anim. Biosci. 4:518. 